ARTICLE

\title{
Enhanced succinic acid production by Mannheimia employing optimal malate dehydrogenase
}

Jung Ho Ahn1,2,3,7, Hogyun Seo (10) 4,5, Woojin Park4,6, Jihye Seok ${ }^{4,6}$, Jong An Lee 1,2,3, Won Jun Kim (10) 1,2,3, Gi Bae Kim (1) 1,2,3, Kyung-Jin Kim (1) ${ }^{4,6 \times}$ \& Sang Yup Lee (1) 1,2,3凶

Succinic acid (SA), a dicarboxylic acid of industrial importance, can be efficiently produced by metabolically engineered Mannheimia succiniciproducens. Malate dehydrogenase (MDH) is one of the key enzymes for SA production, but has not been well characterized. Here we report biochemical and structural analyses of various $\mathrm{MDHs}$ and development of hyper-SA producing M. succiniciproducens by introducing the best MDH. Corynebacterium glutamicum $\mathrm{MDH}(\mathrm{CgMDH})$ shows the highest specific activity and least substrate inhibition, whereas M. succiniciproducens $\mathrm{MDH}(\mathrm{MsMDH})$ shows low specific activity at physiological $\mathrm{pH}$ and strong uncompetitive inhibition toward oxaloacetate ( $k i$ of 67.4 and $588.9 \mu \mathrm{M}$ for $\mathrm{MsMDH}$ and $\mathrm{CgMDH}$, respectively). Structural comparison of the two $\mathrm{MDH}$ s reveals a key residue influencing the specific activity and susceptibility to substrate inhibition. A high-inoculum fed-batch fermentation of the final strain expressing cgmdh produces $134.25 \mathrm{~g} \mathrm{~L}^{-1}$ of SA with the maximum productivity of $21.3 \mathrm{gL}^{-1} \mathrm{~h}^{-1}$, demonstrating the importance of enzyme optimization in strain development.

\footnotetext{
${ }^{1}$ Metabolic and Biomolecular Engineering National Research Laboratory, Department of Chemical and Biomolecular Engineering (BK21 Plus Program), Institute for the BioCentury, Korea Advanced Institute of Science and Technology (KAIST), Daejeon 34141, Republic of Korea. ${ }^{2}$ Systems Metabolic Engineering and Systems Healthcare Cross-Generation Collaborative Laboratory, KAIST, Daejeon 34141, Republic of Korea. ${ }^{3}$ Bioinformatics Research Center and BioProcess Engineering Research Center KAIST, Daejeon 34141, Republic of Korea. ${ }^{4}$ School of Life Sciences, KNU Creative BioResearch Group, Kyungpook National University, Daegu 41566, Republic of Korea. ${ }^{5}$ Pohang Accelerator Laboratory, Pohang University of Science and Technology, Pohang, Republic of Korea. ${ }^{6}$ KNU Institute for Microorganisms, Kyungpook National University, Daegu 41566, Republic of Korea. ${ }^{7}$ These authors contributed equally: Jung Ho Ahn, Hogyun Seo. ${ }^{凶}$ email: kkim@knu.ac.kr; leesy@kaist.ac.kr
} 
B o-based production of industrial chemicals from renewable non-food biomass has become increasingly important as a sustainable substitute for conventional petroleum-based production processes relying on fossil resources. Among many chemicals that can be produced biologically, succinic acid (SA), a four-carbon dicarboxylic acid, is one of the most promising platform chemicals serving as a precursor for industrially important chemicals, such as 1,4-butanediol, $\gamma$-butyrolactone, tetrahydrofuran, and as a monomer to manufacture various polymers ${ }^{1}$. Recognizing its importance, much effort has been exerted to metabolically engineer various microorganisms toward development of efficient SA production bioprocesses ${ }^{1}$. Moreover, companies such as Ajinomoto $^{2}$, Myriant ${ }^{3}$, Reverdia ${ }^{4}$, and Succinity ${ }^{5}$ have successfully established demo plant-scale bio-based SA production, seeking its commercialization ${ }^{1}$.

Various microorganisms, including Actinobacillus succinogenes $^{6}$, Corynebacterium glutamicum ${ }^{7}$, Escherichia coli ${ }^{8}$, Mannheimia succiniciproducens ${ }^{9}$ (and Basfia succiniciproducens ${ }^{5}$, which is almost identical to M. succiniciproducens in genome sequence), Saccharomyces cerevisiae ${ }^{10}$, and Yarrowia lipolytica ${ }^{11}$ have been studied and engineered to develop SA production bioprocesses. Although significant progress has been made on SA production using C. glutamicum, E. coli, and yeast strains, these non-natural SA producers produce SA with relatively low overall production indices (titer, yield, and productivity) and often rely on dual phase fermentation process comprising aerobic cultivation of cells to a high density followed by switching to anaerobic condition to produce $\mathrm{SA}^{7,12}$. On the other hand, natural SA producers such as A. succinogenes and M. succiniciproducens (B. succiniciproducens) that are capnophilic, Gram-negative, and facultative anaerobic bacteria can efficiently produce SA as a major fermentation product ${ }^{1}$. Thus, these natural SA producers have been suggested as good candidate strains for industrial-scale SA production ${ }^{5,6,9}$.

Among these SA producing microorganisms, M. succiniciproducens has been proven to be one of the best strains for SA production. In our previous studies, energy balance ${ }^{13}$, byproduct pathways elimination ${ }^{14}$, and flux re-routing ${ }^{9}$ based on in silico genome-scale metabolic analyses were performed to enhance SA production in $M$. succiniciproducens. The M. succiniciproducens PALK strain, which was developed by deleting lactate dehydrogenase (LDHA), phosphate acetyltransferase (PTA), and acetate kinase (ACKA) to prevent byproduct formation, produced nearly homo-SA with high productivity ${ }^{15}$. Moreover, various studies including the use of inexpensive carbon sources ${ }^{16}$, membrane engineering for strain robustness ${ }^{17}$, and development of effective fermentation ${ }^{9}$ and downstream processes $^{15}$ were carried out. However, there had been no effort exerted to improve the enzymes to further improve SA production.

In M. succiniciproducens, SA is produced through the reductive branch of tricarboxylic acid (TCA) cycle. The key enzymes involved in SA production were identified to be phosphoenolpyruvate (PEP) carboxykinase (PCKA) that converts PEP to oxaloacetate (OAA) while producing ATP, malate dehydrogenase $(\mathrm{MDH})$ that reduces $\mathrm{OAA}$ to malate using $\mathrm{NADH}$ as a cofactor, fumarase (FUMC) that converts malate to fumarate, and fumarate reductase (FRD) that reduces fumarate to SA using menaquinol as a cofactor (Supplementary Fig. 1 and Supplementary Table 1). Among these key enzymes, the $\mathrm{NAD}^{+} / \mathrm{NADH}$-dependent $\mathrm{MDH}$ was predicted to be important for further engineering as it converts OAA to malate, which is a committed step toward SA biosynthesis (Fig. 1a) ${ }^{18}$. Considering the importance of $\mathrm{MDH}$, there had been studies on the amplification of a heterologous $\mathrm{MDH}$ in E. coli ${ }^{19,20}$ and controlled MDH localization in $S$. cerevisiae $^{21,22}$. However, there had been no studies on systematically characterizing various MDHs. Also, there had been no studies on the role of $\mathrm{MDH}$ in SA production by rumen bacteria, the most efficient SA producers.

Phylogenetic analysis of $\mathrm{MDH}$ from previous study classified this enzyme into two categories: cytosolic and mitochondrial MDHs, as they were found to be localized at different cellular compartments and showed distinctive characteristics ${ }^{23}$. In general, the cytosolic MDHs preferentially participate in malate-aspartate shuttle for $\mathrm{NADH}$ transfer, whereas the mitochondrial MDHs participate in oxidative TCA cycle ${ }^{24,25}$. Thus, the cytosolic MDH seems to be more appropriate for OAA reduction compared with the mitochondrial $\mathrm{MDH}^{26}$. However, the $\mathrm{MDH}$ from the major microorganisms employed for SA overproduction, such as $A$. succinogenes, E. coli, M. succiniciproducens, S. cerevisiae, and $Y$. lipolytica are clustered together with the mitochondrial $\mathrm{MDH}$ family, whereas the C. glutamicum $\mathrm{MDH}$ belongs to the cytosolic MDH family (Supplementary Fig. 2 and Supplementary Data 1). These intriguing results led us to comparatively examine the structural and catalytic characteristics of MDHs.

In this study, we report the results of detailed studies on various MDHs, selection of the best $\mathrm{MDH}$ and subsequent metabolic engineering of M. succiniciproducens, and development of fermentation processes for highly efficient SA production. This strategy of integrating systems metabolic engineering with enzyme engineering will be useful for developing high performance strains for the production of industrially competitive biobased chemicals.

\section{Results}

Kinetic characteristics of various MDHs. In order to find an optimal $\mathrm{MDH}$ for $\mathrm{OAA}$ to malate conversion, eight different MDHs from the most studied and/or industrially employed natural and non-natural SA producers including A. succinogenes (As $\mathrm{MDH}$ ), C. glutamicum (CgMDH), E. coli (EcMDH), M. succiniciproducens (MsMDH), S. cerevisiae (mitochondrial ScMDH1, cytosolic ScMDH2, and glyoxysomal ScMDH3), and Y. lipolytica (cytosolic $Y l \mathrm{MDH})^{27}$ were evaluated. This was because there would be a better chance of finding an optimal MDH from these microorganisms, which potentially bears desirable properties for enhanced SA production in M. succiniciproducens, rather than from other organisms not capable of efficiently producing SA. The physiological roles of these selected MDHs are summarized in Supplementary Note 1. Out of the eight MDHs expressed in E. coli, only four MDHs, including $M s \mathrm{MDH}, C g \mathrm{MDH}, E c \mathrm{MDH}$, and $\mathrm{YlMDH}$, were expressed in soluble form and successfully purified. The OAA reduction activities of four MDHs at $\mathrm{pH} 7.0$ were measured using the purified enzymes. Considering that $M$. succiniciproducens is the most efficient SA producer, it was our surprise to find that $M s \mathrm{MDH}$ exhibited the lowest activity among the four $\mathrm{MDHs}$ compared (Fig. 1b). CgMDH, EcMDH, and $Y l \mathrm{MDH}$ showed 4.4, 1.8, and 2.2fold higher activities than $M s \mathrm{MDH}$, respectively (Fig. 1b). These results were intriguing as $M$. succiniciproducens has been thought to possess a very efficient reductive branch of TCA cycle as it produces SA with high productivity ${ }^{18}$.

Detailed kinetic analyses were performed on $M s \mathrm{MDH}$ and $\mathrm{CgMDH}$ (the $\mathrm{MDH}$ possessing the highest activity) to compare their characteristics. The kinetic analyses were performed using $\mathrm{OAA}$ and NADH as substrates, to focus on the thermodynamically favored reaction, which is the reaction necessary for SA production. First, enzyme activities of $M s \mathrm{MDH}$ and $\mathrm{CgMDH}$ were measured at various $\mathrm{pH}$ of $5.0-10.0$ because the activities of $\mathrm{MDH}$ s have shown to be strongly influenced by $\mathrm{pH}^{28}$ (Fig. 1c). $\mathrm{CgMDH}$ showed high activity at relatively acidic $\mathrm{pH}$ and the highest activity at $\mathrm{pH} 7.0$, whereas $\mathrm{MsMDH}$ showed the highest activity at $\mathrm{pH} 9.0$ and dramatically reduced activity at acidic $\mathrm{pH}$. As the optimal $\mathrm{pH}$ for growth of $M$. succinicproducens is $\mathrm{pH}$ 
a
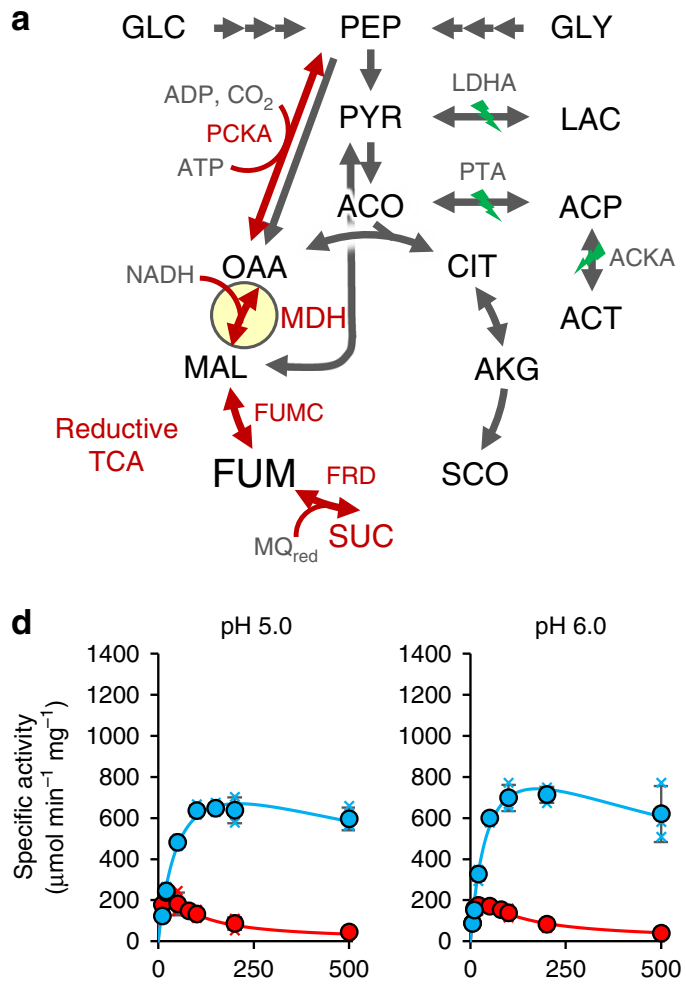

b

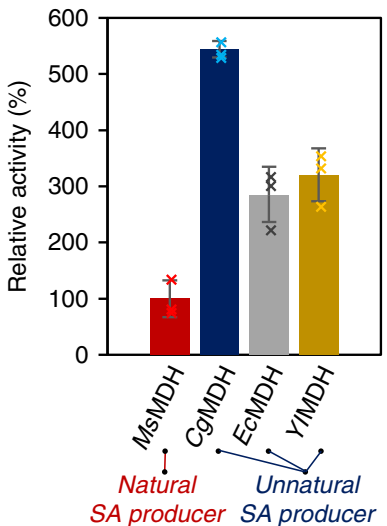

C

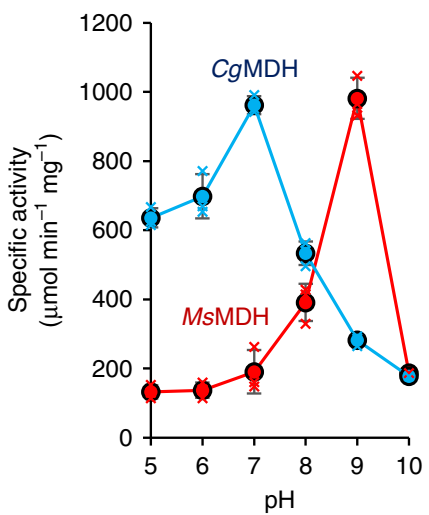

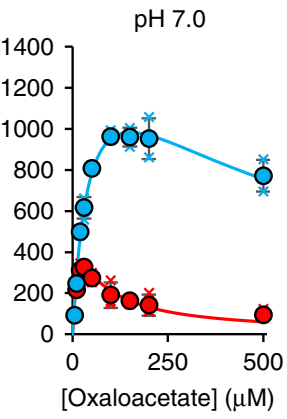
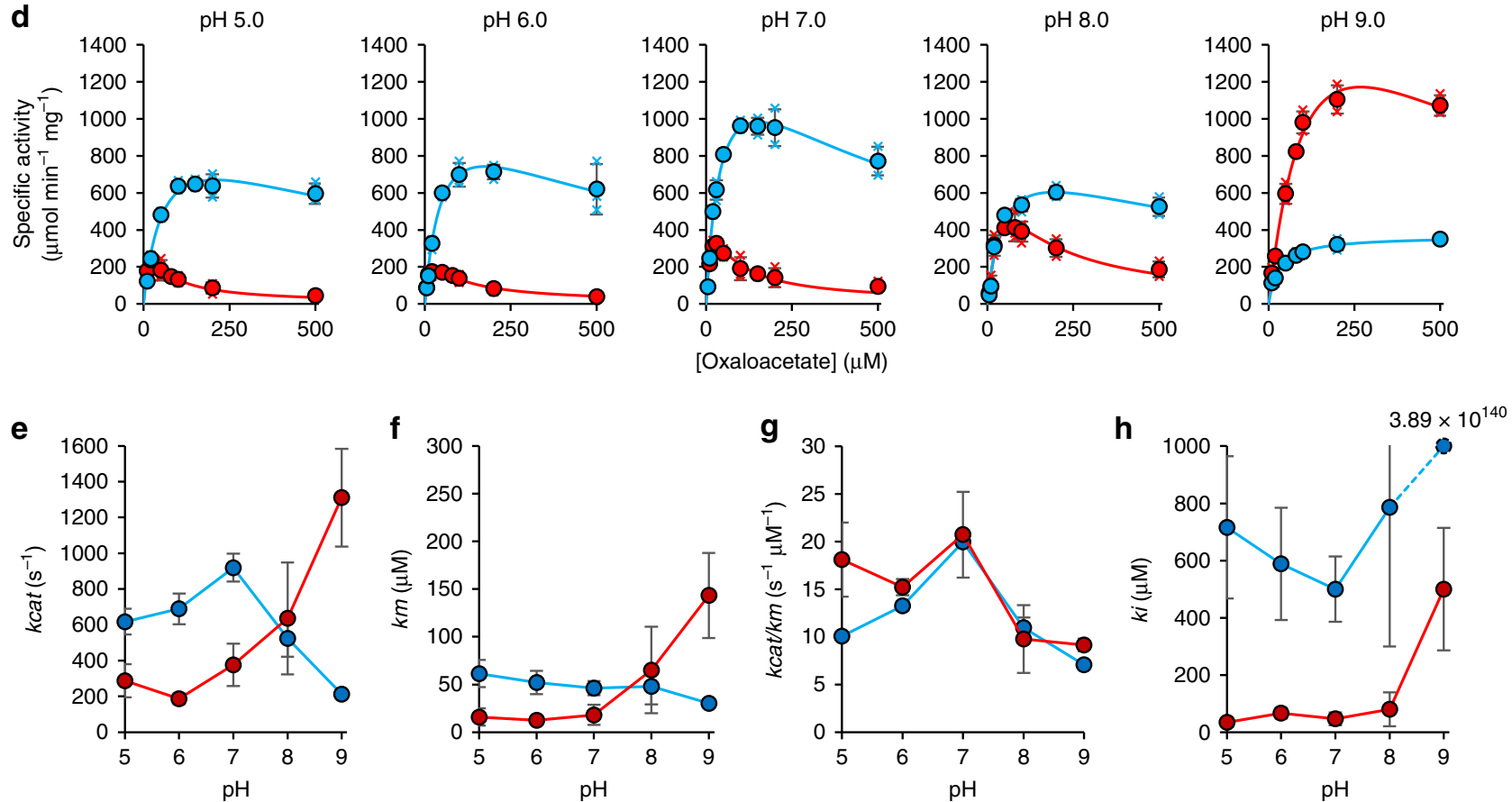

Fig. 1 Comparison of MDH activities. a SA biosynthetic pathway in the M. succiniciproducens PALK strain. Deleted genes are indicated as green thunder symbol. Key enzymes in SA production are indicated as red arrows. GLC glucose, PEP phosphoenolpyruvate, GOL glycerol, PYR pyruvate, LAC lactate, ACO acetyl-CoA, ACP acetyl-phosphate, ACT acetate, OAA oxaloacetate, MAL malate, FUM fumarate, SUC succinate, SCO succinyl-CoA, AKG alphaketoglutarate, CIT citrate, PCKA phosphoenolpyruvate carboxylase, LDHA lactate dehydrogenase, PTA phosphate acetyltransferase, ACKA acetate kinase, $\mathrm{MDH}$ malate dehydrogenase, FUMC fumarate hydratase, FRD fumarate reductase, $M Q_{\text {red }}$ menaquinol. $\mathbf{b}$ The relative activities of four MDHs from various SA producers, including M. succiniciproducens, C. glutamicum, E. coli, and Y. lipolytica, in comparison with the activity of MsMDH ( $n=3$ independent experiments). Data are presented as mean values \pm standard deviation. c Optimal pH of MsMDH and $\mathrm{CgMDH}$ ( $n=3$ independent experiments). Data are presented as mean values \pm standard deviation. The specific activities at $\mathrm{pH} 10.0$ were determined from a single data. $\mathbf{d}$ Catalytic performances of $\mathrm{MsMDH}$ and $\mathrm{CgMDH}$ at different $\mathrm{pH}$ ( $n=3$ independent experiments). Data are presented as mean values \pm standard deviation. e $\mathrm{kcat}, \mathbf{f} \mathrm{km}, \mathbf{g} \mathrm{kcat} / \mathrm{km}$, and $\mathbf{h} \mathrm{ki}$ values of $\mathrm{MsMDH}$ and $\mathrm{CgMDH}$ at different $\mathrm{pH}$. Red and blue lines represent $\mathrm{MsMDH}$ and $\mathrm{CgMDH}$, respectively. The $\mathrm{ki}$ value of $\mathrm{CgMDH}$ at $\mathrm{pH} 9.0$ is shown in number because its value is significantly higher than the rest of the ki values. Data $\mathbf{e}-\mathbf{h}$ are presented as parameters \pm standard error. The standard errors from determining the kinetic parameters using OriginPro 2019 software $(n=$ the number of mean velocity data at specific $\mathrm{pH})$ are shown as bars.

$6.5-7.2^{29,30}$, fermentation has typically been performed at $\mathrm{pH} 6.5$, which is the lowest $\mathrm{pH}$ for SA production without sacrificing cell growth. Furthermore, the intracellular $\mathrm{pH}$ of $M$. succiniciproducens PALK strain was found to be $6.86 \pm 0.21$ (Supplementary Fig. 3 and Supplementary Table 2). In another study, $\mathrm{CgMDH}$ was identified to be a major enzyme for OAA reduction in C. glutamicum under both aerobic and anaerobic conditions, whereas the membraneassociated malate:quinone oxidoreductase (MQO) in C. glutamicum has a major role in malate oxidation to OAA instead of $C g \mathrm{MDH}^{31}$. Thus, the above results on $\mathrm{MDH}$ activities suggest that $\mathrm{CgMDH}$ will likely be more effective than $M s \mathrm{MDH}$ for SA production in M. succinicproducens.

Quasi-steady-state kinetic analyses of $M s \mathrm{MDH}$ and $\mathrm{CgMDH}$ were also performed at various $\mathrm{pH}$ to determine their kinetic parameters (Fig. 1d-h and Table 1). At pH 5.0-7.0, CgMDH exhibited significantly higher kcat compared with $M s \mathrm{MDH}$, which is consistent with the results of the optimal $\mathrm{pH}$ study above (Fig. 1c and Table 1). However, the $\mathrm{km}$ values of $M s \mathrm{MDH}$ were lower than those of $\mathrm{CgMDH}$ at $\mathrm{pH}$ 5.0-7.0, resulting in similar catalytic efficiencies $(\mathrm{kcat} / \mathrm{km})$ between $M s \mathrm{MDH}$ and $\mathrm{CgMDH}$ 


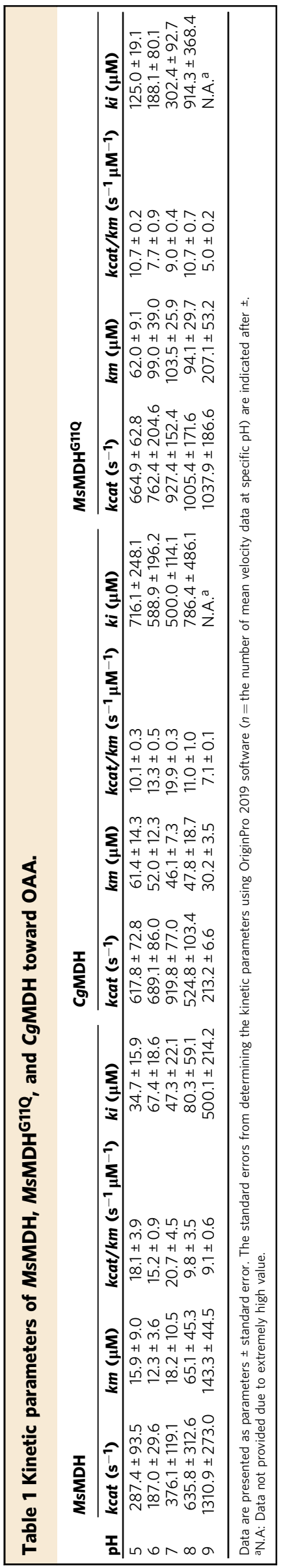

(Fig. 1e-g and Table 1). It was notable that both $M s \mathrm{MDH}$ and $\mathrm{CgMDH}$ were inhibited by OAA (Fig. 1d); these characteristics are similar to those reported for other $\mathrm{MDHs}^{32-35}$. In particular, $M s \mathrm{MDH}$ activity was significantly reduced by substrate inhibition under acidic and neutral $\mathrm{pH}$, showing much lower $k i$ values than CgMDH throughout the entire $\mathrm{pH}$ range (Fig. 1d, h, and Table 1). The intracellular OAA concentration in $M$. succiniciproducens PALK strain was $26.11 \pm 4.47 \mu \mathrm{M}$, confirming that substrate inhibition of $M s \mathrm{MDH}$ occurred in the cell (Fig. 1h, Supplementary Figs. 4, 5, Table 1, and Supplementary Tables 3-5). On the other hand, $C g \mathrm{MDH}$ activity was reduced only to a small degree due to relatively mild substrate inhibition as reflected by its high $k i$ values over the entire $\mathrm{pH}$ range (Fig. $1 \mathrm{~d}, \mathrm{~h}$, and Table 1). It is notable that substrate inhibition of $M s \mathrm{MDH}$ tends to be alleviated with increasing $\mathrm{pH}$, showing a pattern similar to its $\mathrm{pH}$ dependent activity (Fig. $1 \mathrm{~d}-\mathrm{h}$ and Table 1). Taken together, $M s \mathrm{MDH}$ showing low $k c a t$ and $k i$ values at $\mathrm{pH} 5.0-7.0$ is not likely the best $\mathrm{MDH}$ for the production of SA by $M$. succinicproducens PALK strain having a physiological $\mathrm{pH}$ of 6.5-7.0 and an intracellular OAA concentration of $26.11 \pm$ $4.47 \mu \mathrm{M}$. Instead, $\mathrm{CgMDH}$ showing high $k c a t$ and $k i$ values at $\mathrm{pH}$ 5.0-7.0 is a better $\mathrm{MDH}$ for enhanced SA production in $M$. succiniciproducens.

Structural and kinetic analyses of $\mathbf{M s M D H}$ and $C g \mathrm{MDH}$. The crystal structures of $M s \mathrm{MDH}$ and $C g \mathrm{MDH}$ were determined (Supplementary Fig. 6 and Supplementary Table 6) and detailed structural comparison was carried out. As enzyme active site is directly related to kinetic properties, the crystal structures of $\mathrm{MsMDH}$ and $\mathrm{CgMDH}$ were superimposed to find structural differences near the active sites (Supplementary Fig. 7). The two structures, representing the mitochondrial and cytosolic MDHs, were identified to be quite different from each other with a rootmean-square deviation value of 2.77 (Supplementary Fig. 7). Noticeable differences in the substrate (OAA or malate) and cofactor (NADH or $\mathrm{NAD}^{+}$) binding sites of $M s \mathrm{MDH}$ and $\mathrm{CgMDH}$ were found from the conformation of mobile loop ${ }^{36}$ and the lengths of $\beta 7-\beta 8, \alpha 2-\beta 2$, and $\alpha 7-\alpha 8$ connecting loops (Supplementary Fig. 8). The $\beta 7-\beta 8, \alpha 2-\beta 2$, and $\alpha 7-\alpha 8$ connecting loops include a catalytic histidine residue, the NADH-stabilizing residues, and the OAA-binding residues, respectively (Supplementary Fig. 8). As the connecting loops are directly involved in catalysis and substrate-binding, it was speculated that the structural differences between $M s \mathrm{MDH}$ and $\mathrm{CgMDH}$ were responsible for significant differences in enzyme kinetics. However, such kinetic discrepancy is an outcome of complex combinatorial effect of the whole enzyme structure. Thus, the reason for such difference in enzyme kinetics cannot be simply identified by enzyme mutagenesis study. Instead, differences of amino acid residues in the two MDHs were analyzed to identify a key residue that affects the performance of OAA reduction (Fig. 2a, b).

Comparative analysis of the OAA and malate binding site (the a7-a8 connecting loop) revealed that Ala224 in $M s \mathrm{MDH}$ corresponded to Ser242 in CgMDH (Fig. 2a,b). Also, Leu101 in $M s \mathrm{MDH}$, a residue involved in the binding of adenine moiety of $\mathrm{NADH}$, corresponded to Gln 117 in $C g \mathrm{MDH}$ (Fig. 2a, b). Presence of a protruding Gln20 in $C g \mathrm{MDH}$ was also observed at the pyrophosphate moiety binding site, whereas $M s \mathrm{MDH}$ was found to possess Gly11 instead (Fig. 2a, b). Based on three residual differences, each of these three residues differently found in $M s \mathrm{MDH}$ and $\mathrm{CgMDH}$ were swapped at the corresponding site to construct six mutant MDHs for key residue identification. The relative activities of OAA reduction by six $M s \mathrm{MDH}$ and $\mathrm{CgMDH}$ variants, except for the $M s \mathrm{MDH}^{\mathrm{A} 224 \mathrm{~S}}$ variant, which formed inclusion bodies in E. coli, were analyzed in comparison with the 
a

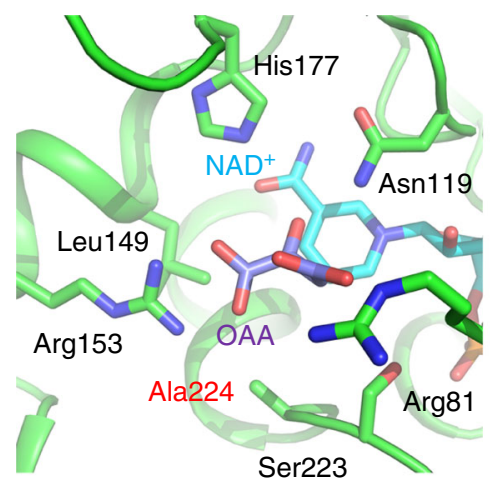

b

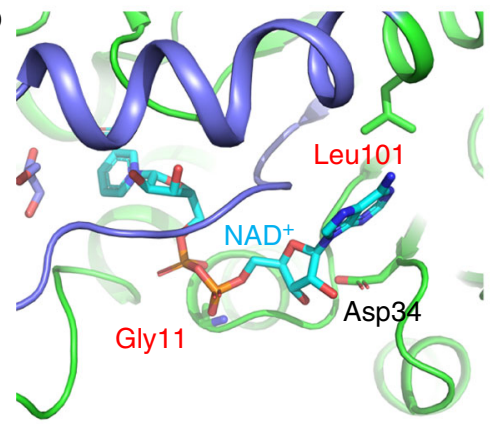

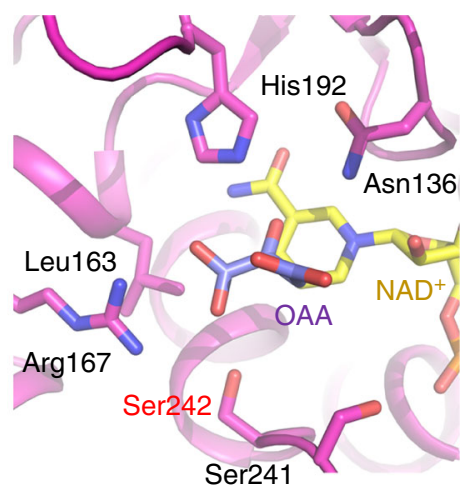

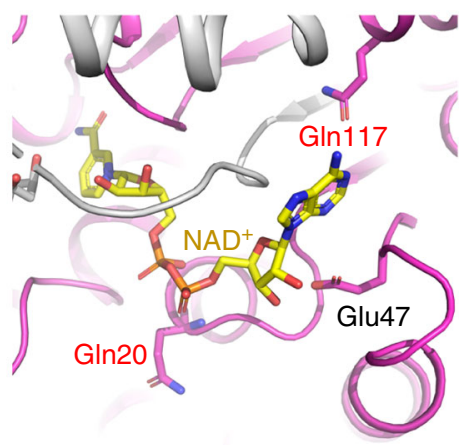

C

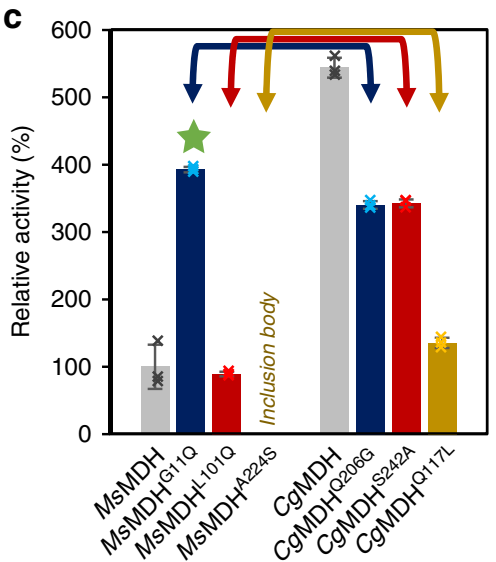

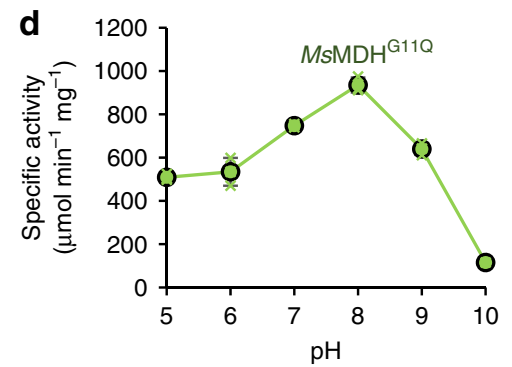
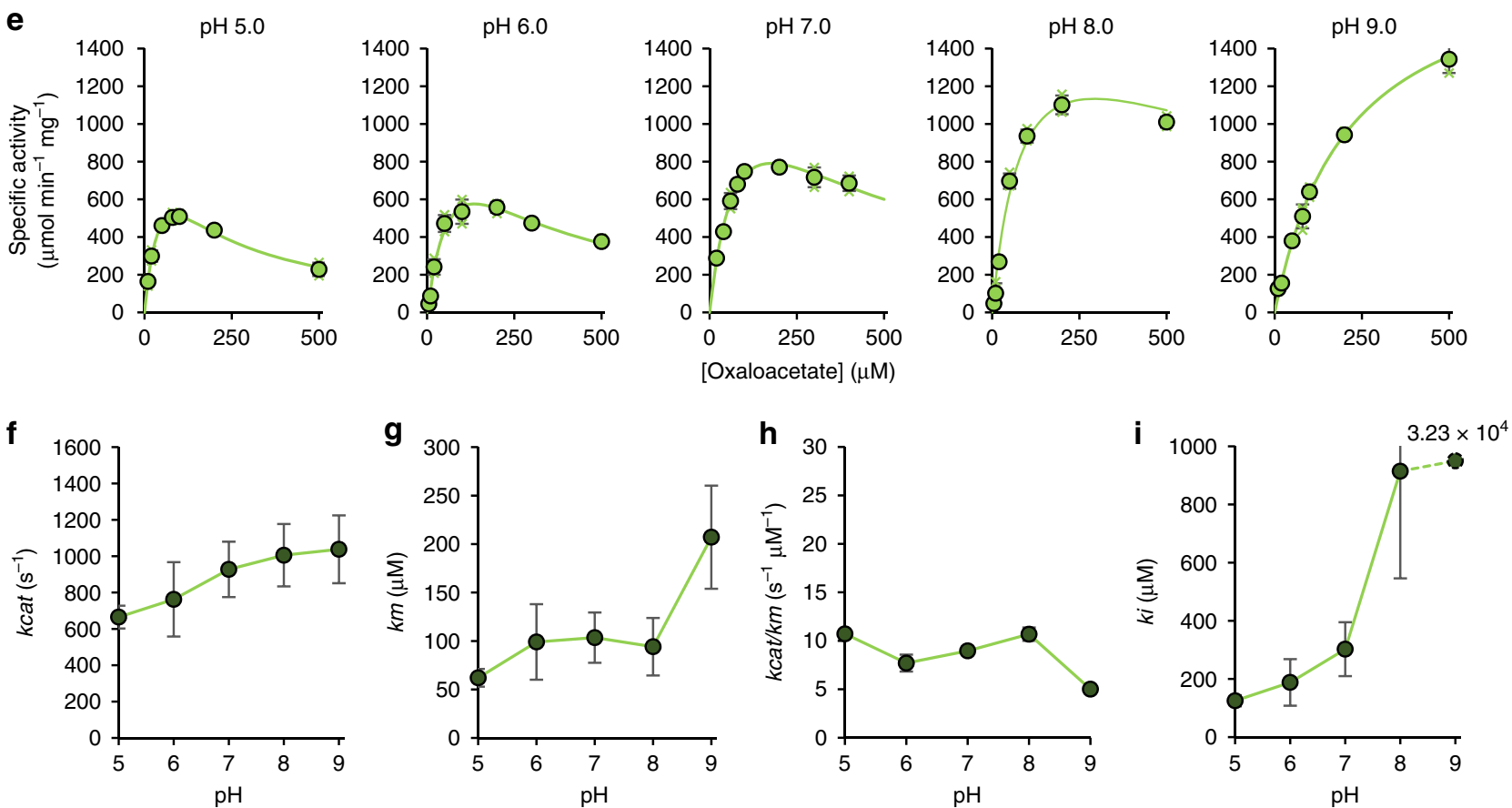

Fig. 2 Development of highly efficient $\mathbf{M s} \mathbf{M D H}^{\mathbf{G} 110}$ variant based on structural comparison between $\mathbf{M s M D H}$ and $\mathbf{C g M D H}$. a The OAA/malate binding site and $\mathbf{b} \mathrm{NADH} / \mathrm{NAD}^{+}$binding site of the two crystal structures; MsMDH (left, green model) and $\mathrm{CgMDH}$ (right, magenta model). The conformation of OAA is obtained from a superimposed structure of Methylobacterium extorquens MDH (PDB code 4ROS). The mobile loop is distinguished by different color schemes of light blue $(\mathrm{MsMDH})$ and gray $(\mathrm{CgMDH})$. The observed residual differences are indicated by red color. c Site-directed mutagenesis and the relative activities of the $\mathrm{MsMDH}$ and $\mathrm{CgMDH}$ variants in comparison with the activity of $\mathrm{MsMDH}$ ( $n=3$ independent experiments). Data are presented as mean values \pm standard deviation. Each of the corresponding variants are indicated by the same color scheme and arrow. The MsMDH ${ }^{\mathrm{A} 224 \mathrm{~S}}$ variant, which is labeled as 'Inclusion body', was expressed insoluble. The MsMDH ${ }^{\mathrm{G} 11 \mathrm{Q}}$ variant is indicated by a green star. $\mathbf{d}$ Optimal pH of the MsMDH $\mathrm{M}^{\mathrm{N}} \mathrm{Q}$ variant $(n=3$ independent experiments). Data are presented as mean values \pm standard deviation. The specific activity at pH 10.0 was determined from a single data. e Catalytic performance of the $\mathrm{MsMDH}^{\mathrm{G} 11 \mathrm{Q}}$ variant at different $\mathrm{pH}$ ( $n=3$ independent experiments). Data are presented as mean values \pm standard

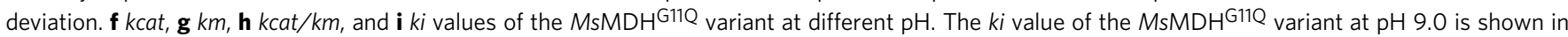
number because its value is significantly higher than the rest of the ki values. Data $\mathbf{f}-\mathbf{i}$ are presented as parameters \pm standard error. The standard errors from determining the kinetic parameters using OriginPro 2019 software ( $n=$ the number of mean velocity data at specific $\mathrm{pH}$ ) are shown as bars. 
activity of $M s \mathrm{MDH}$ at $\mathrm{pH} 7.0$ and compared with those of the wild-type enzymes. One of the variants, $M s \mathrm{MDH}^{\mathrm{G} 11 \mathrm{Q}}$, showed 2.9-fold higher activity compared with $M s \mathrm{MDH}$, whereas the activity of the $C g \mathrm{MDH}^{\mathrm{Q} 20 \mathrm{G}}$ variant (the counterpart variant of $M s \mathrm{MDH}^{\mathrm{G} 11 \mathrm{Q}}$ ) was reduced compared with $\mathrm{CgMDH}$ (Fig. 2c). All the other variants showed reduced activities compared with their corresponding wild-type MDHs (Fig. 2c). These results suggested that the replacement of Gly11 in $M s \mathrm{MDH}$ with Gln (e.g., Gln20 of $\mathrm{CgMDH}$ ) endowed $\mathrm{MsMDH}$ with high overall catalytic performance observed with $C g \mathrm{MDH}$ (Fig. 2c). A study on kinetic analysis of the $\mathrm{MDH}$ from Phycomyces blakesleeanus, which is known to have glycine residue at its 11 th position, revealed that substrate inhibition prevents $\mathrm{NADH}$ binding ${ }^{34}$. This finding is similar to our result in that the change in NADH binding motif (replacement of Gly11 MsMDH with Gln) affected substrate inhibition. However, kinetic studies on $M s \mathrm{MDH}$ and the $M s \mathrm{MDH}^{\mathrm{G} 11 \mathrm{Q}}$ variant toward NADH revealed similar results with those of mitochondrial MDH from Cryptococcus neoformans, which exhibited uncompetitive substrate inhibition (Supplementary Fig. 9 and Supplementary Table 7$)^{35}$.

Next, detailed kinetic characteristics of the $M s \mathrm{MDH}^{\mathrm{G} 11 \mathrm{Q}}$ variant were analyzed at pH 5.0-9.0 (Fig. 2d-i). First, the optimal activity of the $M s \mathrm{MDH}^{\mathrm{G} 11 \mathrm{Q}}$ variant was observed at $\mathrm{pH} 8.0$ (Fig. 2d), which was reduced below the optimal $\mathrm{pH}$ of wild-type $M s \mathrm{MDH}$ (Fig. 1c). Second, the kcat values were significantly increased for the entire $\mathrm{pH}$ range examined (Fig. $2 \mathrm{f}$ and Table 1 ). Third, the $M s \mathrm{MDH}^{\mathrm{G} 11 \mathrm{Q}}$ variant showed reduced susceptibility to substrate inhibition represented by higher $k i$ value (Fig. $2 \mathrm{i}$ and Table 1). Fourth, the $\mathrm{km}$ values were significantly increased and the catalytic efficiency was reduced compared with $M s \mathrm{MDH}$ (Fig. 2g, h and Table 1). Although the fourth characteristic of the $M s \mathrm{MDH}^{\mathrm{G} 11 \mathrm{Q}}$ variant is undesirable, the other three improved characteristics, in particular higher $k c a t$ and $k i$ values, suggest that this variant might be superior to $M s M D H$. In summary, a key residue for high kinetic efficiency in $M s \mathrm{MDH}$ was discovered and the $M s \mathrm{MDH}^{\mathrm{G} 11 \mathrm{Q}}$ variant with high activity and less substrate inhibition compared with its wild type was developed based on comparative structural analysis of $M s \mathrm{MDH}$ and $\mathrm{CgMDH}$.

SA production by employing $C g \mathrm{MDH}$ and $M s \mathrm{MDH}^{\mathrm{G} 11 \mathrm{Q}}$ variant. Fed-batch fermentations of the engineered strains employing the highly catalytic MDHs, $C g \mathrm{MDH}$ or $M s \mathrm{MDH}^{\mathrm{G} 11 \mathrm{Q}}$ variant, were performed to evaluate the actual SA production performances. It should be mentioned that all fed-batch fermentations were performed in duplicate to confirm reproducibility.

Before testing the effect of replacing $M s \mathrm{MDH}$ with $\mathrm{CgMDH}$ or $M s \mathrm{MDH}^{\mathrm{G} 11 \mathrm{Q}}$ variant on $\mathrm{SA}$ production in vivo, we first examined whether $m s m d h$ gene overexpression is beneficial to SA production. In silico simulation suggested that reinforcement of metabolic flux from OAA to malate is advantageous for enhanced SA production (Supplementary Fig. 1 and Supplementary Table 1). Thus, the PALK strain ${ }^{15}$ overexpressing the $m s m d h$ gene was developed (Supplementary Tables 8, 9). Fed-batch fermentation of the PALK (pMS3-msmdh) strain in a chemically defined medium (CDM) using glucose as a carbon source produced $79.07 \mathrm{~g} \mathrm{~L}^{-1}$ of SA with the yield and productivity of $1.23 \mathrm{~mol} \mathrm{~mol}^{-1}$ glucose and $3.26 \mathrm{~g} \mathrm{~L}^{-1} \mathrm{~h}^{-1}$, respectively (Supplementary Fig. 10a and Supplementary Data 2). For comparison, fed-batch fermentation of the PALK (pMS3) strain, the PALK strain harboring an empty vector, produced $74.56 \mathrm{~g} \mathrm{~L}^{-1}$ of SA with yield and productivity of $1.11 \mathrm{~mol}$ $\mathrm{mol}^{-1}$ glucose and $3.03 \mathrm{~g} \mathrm{~L}^{-1} \mathrm{~h}^{-1}$, respectively, under the same fedbatch culture condition (Supplementary Data 2) ${ }^{17}$. Overexpression of $m s m d h$ in the PALK strain enhanced SA production as predicted by in silico simulation, but the improvement was not significant. To examine whether expressing the gene encoding one of the two highly efficient $\mathrm{MDHs}, \mathrm{CgMDH}$ and the $M s \mathrm{MDH}^{\mathrm{G}} 11 \mathrm{Q}$ variant, allows enhanced SA production, two engineered M. succiniciproducens PALK strains expressing the corresponding genes (cgmdh and $m s m d h^{\mathrm{G} 11 \mathrm{Q}}$ ) were constructed (Supplementary Tables 8,9 ). Fed-batch culture of the PALK (pMS3-cgmdh) strain produced $87.23 \mathrm{~g} \mathrm{~L}^{-1}$ of SA with yield and productivity of $1.29 \mathrm{~mol} \mathrm{~mol}^{-1}$ glucose and $3.6 \mathrm{~g} \mathrm{~L}^{-1} \mathrm{~h}^{-1}$, respectively (Supplementary Fig. 10b and Supplementary Data 2); the titer, yield, and productivity all significantly increased by amplifying the cgmdh gene. These results suggest that increasing conversion rate of OAA to malate by $\mathrm{CgMDH}$ possessing 4.4-fold higher activity than $\mathrm{MsMDH}$ (Fig. 1b) as well as much less substrate inhibition (Fig. 1d) at physiological conditions ( $\mathrm{pH}$ and OAA concentration) was both advantageous for enhanced SA production. The beneficial effect of employing highly efficient $C g \mathrm{MDH}$ was also tested in wild-type C. glutamicum and E. coli strains, which are widely used in the industry for chemicals production. Both engineered strains overexpressing cgmdh showed enhanced SA production (Supplementary Table 10), suggesting that the highly active $C g \mathrm{MDH}$ is indeed beneficial for enhancing the conversion of OAA to malate regardless of the microbial strain.

Next, two PALK derivative strains expressing the $c g m d h^{\mathrm{Q} 20 \mathrm{G}}$ (encoding $C g \mathrm{MDH}^{\mathrm{Q} 20 \mathrm{G}}$ ) and $m s m d h^{\mathrm{G} 11 \mathrm{Q}}$ genes were constructed (Supplementary Tables 8,9 ) to compare the effect of expressing the $m s m d h^{\mathrm{G} 11 \mathrm{Q}}$ gene and its counterpart variant $\left(c g m d h^{\mathrm{Q} 20 \mathrm{G}}\right)$ gene on SA production. Fed-batch fermentation of the PALK (pMS3cgmdh ${ }^{\mathrm{Q} 20 \mathrm{G}}$ ) strain produced $79.39 \mathrm{~g} \mathrm{~L}^{-1}$ of SA with the yield and productivity of $1.0 \mathrm{~mol} \mathrm{~mol}^{-1}$ glucose and $3.27 \mathrm{~g} \mathrm{~L}^{-1} \mathrm{~h}^{-1}$, respectively (Supplementary Fig. 10c and Supplementary Data 2). The SA production performance had significantly decreased compared with the PALK (pMS3-cgmdh) strain, indicating decreased catalytic performance of substituting Gln20 of $C g \mathrm{MDH}$ with glycine (Fig. 2c). On the other hand, fed-batch fermentation of the PALK (pMS3msmdh ${ }^{\mathrm{G} 11 \mathrm{Q}}$ ) strain produced $84.19 \mathrm{~g} \mathrm{~L}^{-1}$ of SA with the yield and productivity of $1.08 \mathrm{~mol} \mathrm{~mol}^{-1}$ glucose, and $3.48 \mathrm{~g} \mathrm{~L}^{-1} \mathrm{~h}^{-1}$, respectively (Supplementary Fig. 10d and Supplementary Data 2), which is an improved SA production performance compared with the PALK (pMS3-msmdh) strain (Supplementary Fig. 10a and Supplementary Data 2). This result suggests that the $M s \mathrm{MDH}^{\mathrm{G} 11 \mathrm{Q}}$ variant allows more efficient in vivo conversion of OAA to malate compared with $M s \mathrm{MDH}$. Taken together, the expression of a gene encoding the superior $C g \mathrm{MDH}$ or the $M s \mathrm{MDH}^{\mathrm{G} 11 \mathrm{Q}}$ variant, instead of $M s \mathrm{MDH}$, in M. succiniciproducens, which consequently led to enhanced SA production. Also, the importance of glutamine residue at the position of Gln 20 in $C g \mathrm{MDH}$ and Gly11 in $M s \mathrm{MDH}$ in enhanced conversion of OAA to malate was confirmed in vivo.

Recombinant strains harboring plasmids are not preferred in industrial fermentation due to the possibility of plasmid instability in the absence of antibiotic selection pressure ${ }^{37}$. Thus, we pursued to construct a plasmid-free SA producer by chromosomal integration of the superior $c g m d h$ or $m s m d h \mathrm{G} 11 \mathrm{Q}$ gene. The PALKcgmdh and PALKmsmdhG11Q strains were constructed by replacing the $m s m d h$ gene in the PALK strain genome with the $c g m d h$ or $m s m d h^{\mathrm{G} 11 \mathrm{Q}}$ gene under the stronger frd promoter (Supplementary Tables 8, 9; see Methods for chromosomal integration $)^{38}$. The SA production performance indices obtained with fed-batch fermentation of the PALKcgmdh (Supplementary Fig. 10e and Supplementary Data 2) and PALKmsmdhG11Q (Supplementary Fig. 10f and Supplementary Data 2) strains in CDM containing glucose were comparable to those achieved with the PALK (pMS3-cgmdh) (Supplementary Fig. 10b) and PALK (pMS3-msmdhG11Q) (Supplementary Fig. 10d) strains, respectively, which express the $m d h$ genes from the plasmids. It is interesting to observe that chromosomal replacement of the $m s m d h$ with $c g m d h$ or $m s m d h^{\mathrm{G} 11 \mathrm{Q}}$ allowed high SA production similar to those achieved by the PALK 
(pMS3-cgmdh) and PALK (pMS3-msmdhG11Q) strains, even though these latter strains additionally harbor $m s m d h$ gene in the chromosome. Thus, enhanced SA production by the PALK (pMS3-cgmdh) and PALK (pMS3-msmdhG11Q) strains seems primarily due to the introduction of $C g \mathrm{MDH}$ or $M s \mathrm{MDH}^{\mathrm{G} 11 \mathrm{Q} \text {, }}$ both of which possess higher kcat and ki values than $M s \mathrm{MDH}$. In addition, fed-batch fermentation of the PALKPfrdmsmdh strain, which was constructed by replacing the native promoter of msmdh gene with the frd promoter in the PALK strain, showed similar SA production performance with the PALK strain (Supplementary Fig. 11 and Supplementary Data 2), suggesting that the enhanced SA production by replacing $m s m d h$ with $c g m d h$ or $m s m d h \mathrm{G} 11 \mathrm{Q}$ was not due to the use of stronger frd promoter, but rather because of the higher MDH activity. Furthermore, specific activity of the cell extract of PALKcgmdh strain was 1.5 -fold higher than that of the PALK strain, suggesting that the replacement of $m s m d h$ gene with the cgmdh gene in $M$. succiniciproducens genome is beneficial for SA production (Supplementary Fig. 12).

Optimizing culture condition to improve SA production. To further improve SA production by fed-batch fermentations of the PALKcgmdh and PALKmsmdh G11Q strains, culture conditions were optimized. Based on our previous studies, glucose and glycerol were used as dual carbon sources to enhance SA production by taking full advantage of a highly efficient $C g \mathrm{MDH}$ or $M s \mathrm{MDH} \mathrm{H}^{\mathrm{G} 11 \mathrm{Q}}$ through providing more reducing equivalents ${ }^{9,39}$; conversion of glycerol (C3) to PEP (C3) generates twice as much reducing equivalents per sixcarbon equivalent mole compared with glucose (C6) ${ }^{40}$. Metabolic fluxes of the PALK strain generated from glucose or glucose plus glycerol were compared using in silico simulation to verify enhanced $\mathrm{NADH}$ generation (glycerol 3-phosphate dehydrogenase and glyceraldehyde 3-phosphate dehydrogenase reactions). In silico simulation (Supplementary Fig. 13) and kinetic studies on $M s \mathrm{MDH}$ and the $M s \mathrm{MDH}^{\mathrm{G} 11 \mathrm{Q}}$ variant (Supplementary Fig. 9 and Supplementary Table 7) suggested that the OAA to malate conversion flux increased through the elevated supply of NADH. Fed-batch fermentation of the PALKcgmdh strain in CDM using glucose and glycerol as dual carbon sources produced $101.18 \mathrm{~g} \mathrm{~L}^{-1}$ of $\mathrm{SA}$ with the yield and productivity of $1.37 \mathrm{~mol} \mathrm{~mol}^{-1}$ glucose equivalent (mol SA per mol glucose equivalent) and $4.18 \mathrm{~g} \mathrm{~L}^{-1} \mathrm{~h}^{-1}$, respectively (Fig. 3a and Supplementary Data 2). These results were similar to those obtained by fed-batch fermentation of the plasmid-based PALK (pMS3cgmdh) strain using dual carbon sources (Supplementary Data 2). On the other hand, fed-batch fermentation of the PALKmsmdhG11Q strain in a CDM using dual carbon sources produced $92.5 \mathrm{~g} \mathrm{~L}^{-1}$ of SA with the yield and productivity of $1.28 \mathrm{~mol} \mathrm{~mol}^{-1}$ glucose equivalent and $3.82 \mathrm{~g} \mathrm{~L}^{-1} \mathrm{~h}^{-1}$, respectively (Fig. $3 \mathrm{~b}$ and Supplementary Data 2). Although SA production did not improve as much as the PALKcgmdh strain, the overall SA production indices were significantly increased compared with the previously reported PALK strain cultured under the same condition (Supplementary Data 2) ${ }^{15}$. Taken together, the PALKcgmdh strain showed the best SA production performance, and thus was used for further studies.

One of the fermentation characteristics of M. succiniciproducens is its low cell density during the fermentation. In the cases of the PALK (pMS3), PALKPfrdmsmdh, PALK (pMS3-msmdh), PALK (pMS3cgmdh), PALK (pMS3-msmdh G11Q), PALK (pMS3-cgmdhQ20G), PALKmsmdhG11Q, and PALKcgmdh strains, the maximum cell densities reached during fermentations using glucose were $4.87,4.56$, $4.87,3.53,3.21,3.27,4.46$, and 3.26 gDCW L $^{-1}$, respectively. On the other hand, the specific SA productivities obtained for these strains were $0.62,0.67,0.67,1.02,1.08,1.0,0.76$, and $1.17 \mathrm{~g} \mathrm{gDCW}^{-1} \mathrm{~h}^{-1}$, respectively (Supplementary Data 2 ). Due to exceptionally high specific SA productivities of these engineered strains, the overall
SA productivities are very high even though cell densities reached were far lower than other SA producers such as $E$. coli and $C$. glutamicum (Discussion). As cells are themselves biofactories, the overall productivity can be further increased if cell density is increased. Thus, higher cell density inoculums (the $\mathrm{OD}_{600}$ of 21.1 equivalent to $9.52 \mathrm{gDCW} \mathrm{L}^{-1}$ for PALK and the $\mathrm{OD}_{600}$ of 19.3 equivalent to $8.7 \mathrm{gDCW} \mathrm{L}^{-1}$ for PALKcgmdh) were employed for SA production by fed-batch cultures (Fig. 3c, d). High-inoculum fed-batch culture of the PALK strain produced $98.28 \mathrm{~g} \mathrm{~L}^{-1}$ of SA, with the yield, overall productivity, and maximum productivity of $0.93 \mathrm{~mol} \mathrm{~mol}^{-1}$ glucose, 8.93 and $18.4 \mathrm{~g} \mathrm{~L}^{-1} \mathrm{~h}^{-1}$ (Supplementary Data 2), respectively, using dual carbon sources. The specific SA productivity obtained with high-inoculum fed-batch culture was $0.94 \mathrm{~g} \mathrm{gDCW}^{-1} \mathrm{~h}^{-1}$, similar to that obtained with normal fed-batch culture $\left(1.0 \mathrm{~g} \mathrm{gDCW}^{-1} \mathrm{~h}^{-1}\right)$. In the case of the PALKcgmdh strain, the overall and maximum SA productivities were significantly increased to 10.33 and $21.3 \mathrm{~g} \mathrm{~L}^{-1} \mathrm{~h}^{-1}$, respectively, using dual carbon sources (Supplementary Data 2) due to the strain's superior specific SA productivity of $1.19 \mathrm{ggDCW}^{-1} \mathrm{~h}^{-1}$. In addition, the PALKcgmdh strain produced $134.25 \mathrm{~g} \mathrm{~L}^{-1}$ of SA with almost no byproduct resulting in a yield of $1.25 \mathrm{~mol} \mathrm{~mol}^{-1}$ glucose equivalent (Fig. 3d and Supplementary Data 2). This is the best overall performance reported to date for fermentative SA production ${ }^{1}$. Fermentations of metabolically engineered M. succiniciproducens strains developed in this study were all performed in duplicate to confirm reproducibility and as a standard way of presentation; the results of one representative fed-batch fermentation are shown in the main figure while those of the other fermentations are provided in Supplementary Data 2 and Supplementary Figs. 10 and 14-16.

\section{Discussion}

For the purpose of increasing SA production, $\mathrm{MDH}$ that has important role in directing metabolic flux coming from the anaplerotic pathway toward SA production was investigated. Detailed kinetic analyses of $M s \mathrm{MDH}$ elucidated its low activity at $\mathrm{pH}$ 5.0-8.0 and its high susceptibility to substrate inhibition suggesting that $M s \mathrm{MDH}$ might not be an optimal $\mathrm{MDH}$ for enhanced SA production.

The OAA reduction activity of $\mathrm{CgMDH}$ was significantly higher than those of other mitochondrial MDH-like enzymes (Fig. $1 \mathrm{~b}$ and Supplementary Fig. 2). Functional differences between cytosolic and mitochondrial MDHs are well understood in the malate-aspartate shuttle of eukaryotes ${ }^{26}$. In the shuttle system across mitochondrial inner membrane, whereas OAA reduction activity exists in both cytosolic and mitochondrial MDHs, the cytosolic $\mathrm{MDH}$ is known to have higher preference for converting OAA to malate by $\mathrm{NADH}$ oxidation relative to the mitochondrial $\mathrm{MDH}^{24,25}$, which is consistent with what we observed in this study (Fig. 1a and Supplementary Fig. 2). Moreover, the PALK strain expressing Arabidopsis thaliana cytosolic $\mathrm{MDH}(A t \mathrm{MDHc})$ produced higher amount of SA from fed-batch fermentation using glucose compared to the PALK strain expressing A. thaliana mitochondrial $\mathrm{MDH}$ (At $\mathrm{MDHm1}$ ) suggesting once again that cytosolic $\mathrm{MDH}$ might be a better choice for SA production than mitochondrial $\mathrm{MDH}$ (Supplementary Fig. 16 and Supplementary Data 2). However, $\mathrm{CgMDH}$ was still the best $\mathrm{MDH}$ for highest SA production performance in M. succiniciproducens.

Structural analyses of $C g \mathrm{MDH}$ and $\mathrm{MsMDH}$ provided basis to enhance kcat and to alleviate substrate inhibition of $M s \mathrm{MDH}$. The Gly11 of $M s \mathrm{MDH}$ and Gln20 of $C g \mathrm{MDH}$, which take part in the binding of pyrophosphate moiety of $\mathrm{NADH} / \mathrm{NAD}^{+}$, were identified as a key residue that determines the OAA reduction activity and susceptibility to substrate inhibition (Fig. 1a, b and Table 1). The MsMDHG11Q variant developed based on structural analyses exhibited significantly increased $k c a t$ and higher $k i$ 
a

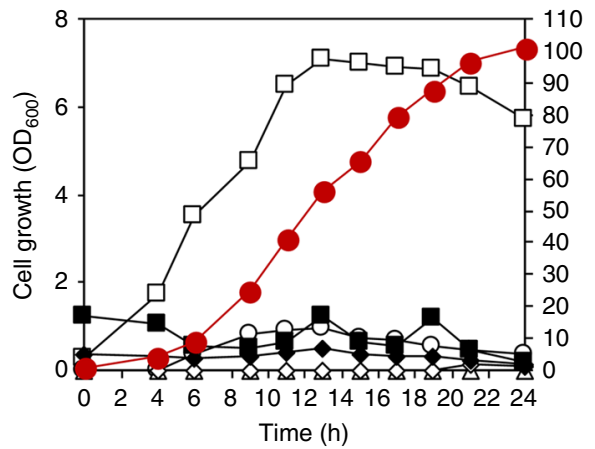

C

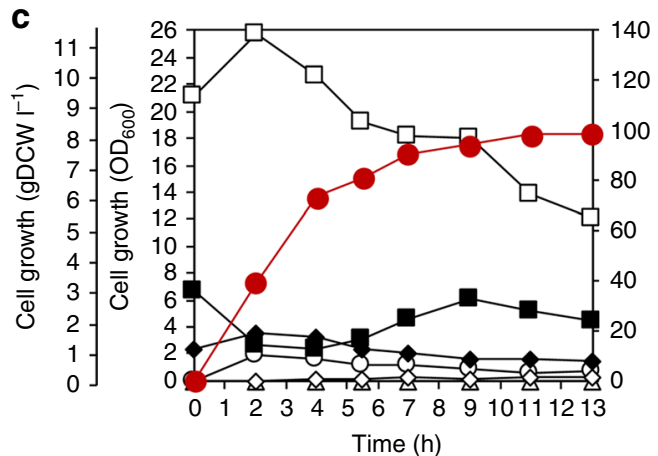

b

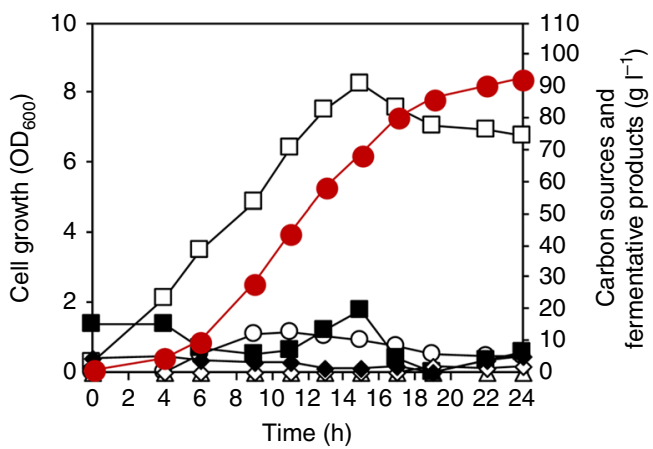

d

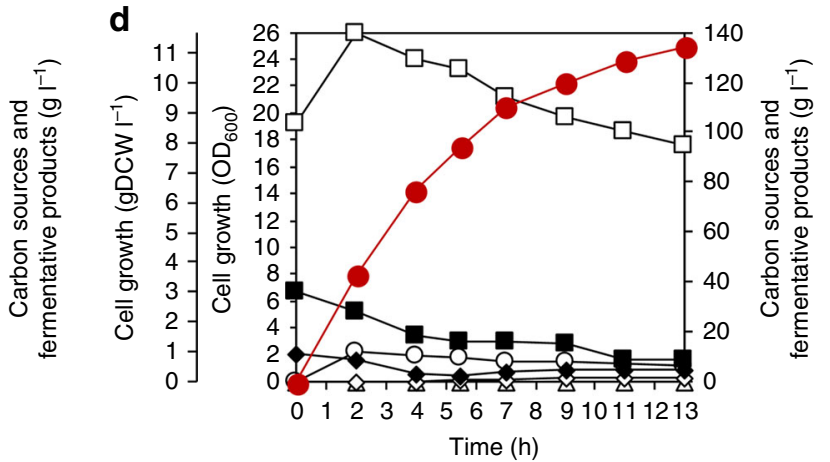

Fig. 3 Fed-batch fermentation profiles of various metabolically engineered $\boldsymbol{M}$. succiniciproducens strains. Fed-batch fermentations of the a PALKcgmdh and $\mathbf{b}$ PALKmsmdh ${ }^{\mathrm{G} 11 \mathrm{Q}}$ strains were carried out in CDM using glucose and glycerol as dual carbon sources. Fed-batch fermentations of the $\mathbf{c}$ PALK and d PALKcgmdh strains were carried out using glucose and glycerol with increased initial cell mass $\left(\mathrm{OD}_{600}=21.1\right.$ and 19.3 , respectively). Symbols: White square, cell growth; red circle, SA; black square, glucose; black diamond, glycerol; white circle, pyruvate; white diamond, acetate; white triangle, formate. Fermentations were all performed in duplicate ( $n=2$ independent experiments). The fermentation profile shown here represents the result of one fedbatch culture, whereas the result of another reproduced fed-batch culture is shown in Supplementary Fig. 15. Source data are provided as a Source Data file.

values compared with its wild type (Table 1). Reduction or elimination of substrate inhibition of several dehydrogenases by single mutation in the active site has been reported ${ }^{41}$.

Replacement of $M s \mathrm{MDH}$ with highly efficient $C g \mathrm{MDH}$ in the M. succiniciproducens PALK strain resulted in the highest overall SA production titer, yield, and productivity reported to date (Supplementary Data 2). Moreover, a bioprocess engineering approach of employing high cell density inoculum fed-batch culture was taken to further increase the overall SA production indices (titer: $134.25 \mathrm{~g} \mathrm{~L}^{-1}$, yield: $1.25 \mathrm{~mol} \mathrm{~mol}^{-1}$ glucose equivalent, productivity: $10.33 \mathrm{~g} \mathrm{~L}^{-1} \mathrm{~h}^{-1}$; Supplementary Data 2). SA production by other microorganisms, such as $E$. coli and $C$. glutamicum, often employs dual phase fermentation technique, which involves aerobic growth phase to reach high cell density first followed by anaerobic production phase to produce SA. The E. coli AFP111 strain expressing the Rhizobium etli pyruvate carboxylase gene was first aerobically grown up to 10.2 gDCW L ${ }^{-1}$ and then subjected to anaerobic condition to produce $99.2 \mathrm{~g} \mathrm{~L}^{-1}$ of SA with an overall productivity of $1.3 \mathrm{~g} \mathrm{~L}^{-1} \mathrm{~h}^{-1}$. The specific SA productivity of $0.14 \mathrm{ggDCW}^{-1} \mathrm{~h}^{-1}$ was obtained ${ }^{12}$. Similarly, C. glutamicum BOL-3 strain overexpressing the glyceraldehyde 3-phosphate dehydrogenase gene was cultured until cell density reached $50 \mathrm{gDCW} \mathrm{L}^{-1}$, then was further cultured under anaerobic condition to produce $134 \mathrm{~g} \mathrm{~L}^{-1}$ of SA with an overall productivity of $2.48 \mathrm{~g} \mathrm{~L}^{-1} \mathrm{~h}^{-1}$. The specific SA productivity of $0.05 \mathrm{~g} \mathrm{gDCW}^{-1} \mathrm{~h}^{-1}$ was obtained ${ }^{7}$. Thus, it can be clearly seen that M. succiniciproducens PALK and MDH amplified PALK strains possess much higher specific SA productivities than these popular SA producers. In addition, introduction of $C g \mathrm{MDH}$ into E. coli and C. glutamicum strains confirmed that the highly active $C g \mathrm{MDH}$ is beneficial for enhanced SA production regardless of the microbial strain (Supplementary Table 10). Although MDH was the focus of this study, it is possible that the introduction of more efficient $C g \mathrm{MDH}$ into M. succiniciproducens might have affected the activities of other enzymes and corresponding reaction fluxes (see Supplementary Note 2 for detailed discussion). As identified from in silico genome-scale metabolic simulation (Supplementary Fig. 1 and Supplementary Table 1), PCKA, FUMC, and FRD can be the next potential candidates to be studied for further enhancing SA production using similar approaches reported here.

In conclusion, we developed a highly efficient SA producing $M$. succiniciproducens strain by integrating the strategies of systems metabolic engineering with enzyme engineering. The use of the best MDH selected from various MDHs through detailed structural and kinetic studies significantly improved SA production. The strategy described in this paper will be useful for developing high performance strains for the production of industrially competitive bio-based chemicals.

\section{Methods}

Strains and plasmids. Strains, plasmids, and oligonucleotides used in this study are listed in Supplementary Tables 8, 9. The E. coli Top10 and E. coli W3110 strains were used as a cloning host for gene manipulation and for SA production, respectively. The E. coli strains were cultivated at $37^{\circ} \mathrm{C}$ in lysogeny broth (LB) medium containing (per L) $10 \mathrm{~g}$ Bacto tryptone, $5 \mathrm{~g}$ yeast extract, and $10 \mathrm{~g} \mathrm{NaCl}$. The C. glutamicum strain was also used for SA production and was cultivated under $30^{\circ} \mathrm{C}$ in BHIS medium containing (per L) $37 \mathrm{~g}$ Bacto Brain Heart Infusion (BHI) medium and $91 \mathrm{~g}$ D-sorbitol. The M. succiniciproducens strains were cultivated under $39^{\circ} \mathrm{C}$ in $\mathrm{BHI}$ medium. The $\mathrm{LB}$ and $\mathrm{BHI}$ plates were prepared by the addition of $1.5 \%(\mathrm{w} / \mathrm{v})$ of agar. When needed, ampicillin $(\mathrm{Ap})$, kanamycin $(\mathrm{Km})$, and chloramphenicol $(\mathrm{Cm})$ were added to the final concentrations of 50,25, and $6.8 \mu \mathrm{g} \mathrm{mL}^{-1}$, respectively, for M. succiniciproducens, and 50, 25, and $24 \mu \mathrm{g} \mathrm{mL}^{-1}$, 
respectively, for E. coli. In the case of C. glutamicum, $25 \mu \mathrm{g} \mathrm{mL} \mathrm{L}^{-1} \mathrm{Km}$ was added to BHIS medium.

To construct pMS3-msmdh, pMS3-msmdh G11Q, pMS3-cgmdh, pMS3cgmdh Q20G, pMS3-atmdhc1, and pMS3-atmdhm1, the msmdh (primers P1-2), $m s m d h h^{\mathrm{G} 11 \mathrm{Q}}$ (primers $\left.\mathrm{P} 1-2\right), c g m d h$ (primers $\left.\mathrm{P} 3-4\right), c g m d h^{\mathrm{Q} 20 \mathrm{G}}$ (primers $\left.\mathrm{P} 3-4\right)$, atmdhc1 (primers P5-6), and atmdhm1 (primers P7-8) gene fragments were prepared by polymerase chain reaction (PCR) with primers listed in Supplementary Tables 8, 9 using M. succiniciproducens genomic DNA, pET30a-msmdhG11Q, C. glutamicum genomic DNA, pET30a-cgmdh ${ }^{\mathrm{Q} 20 \mathrm{G}}$, and A. thaliana genomic DNA respectively, as templates. Each gene fragments were then inserted into pMS3 digested with EcoRI and KpnI using Gibson assembly ${ }^{42}$. To construct p10099Acgmdh, p10099A was digested with EcoRI and PstI and the cgmdh gene fragment was prepared by PCR with primers P18-19. The linearized p10099A and the cgmdh gene fragment were assembled using Gibson assembly. To construct pEKEx1cgmdh, pEKEx1 was digested with EcoRI and PstI and the cgmdh gene fragment was prepared by PCR with primers P20-21. The linearized pEKEx1 and the cgmdh gene fragment were assembled using Gibson assembly. Correct construction of all plasmids developed in this study was verified using DNA sequencing. Plasmids pMS3-msmdh, pMS3-msmdh ${ }^{\mathrm{G} 11 \mathrm{Q}}$, pMS3-cgmdh, pMS3-cgmdh $20 \mathrm{G}$, pMS3atmdhc1, and pMS3-atmdhm1 were transformed to PALK strain ${ }^{43}$.

The M. succiniciproducens PALKcgmdh strain was constructed by replacing $m s m d h$ gene in the PALK strain genome with cgmdh gene. To construct the cgmdh gene integration vector pINcgmdh, the plasmid pSacHR06 containing the $s a c B$ gene was digested with XhoI and SacI. Next, the upstream and downstream homologous regions of the $m s m d h$ gene were amplified from the $M$. succiniciproducens PALK genomic DNA with primers P9-10 and P16-17, respectively. The lox66-cat-lox77 cassette was amplified from pMSmulox with primers P14-15 and the cgmdh gene was amplified from pMS3-cgmdh with primers P11 and P13. The linearized pSacHR06, $1 \mathrm{~kb}$ fragments of the upstream and downstream homologous regions of the msmdh gene, lox66-cat-lox77 cassette, and cgmdh gene fragments were assembled using Gibson assembly to finally construct pINcgmdh. The M. succiniciproducens PALKmsmdh ${ }^{\mathrm{G} 11 \mathrm{Q}}$ strain was constructed by replacing $m s m d h$ gene in the PALK strain with the $m s m d h$ G11Q gene. The $m s m d h^{\mathrm{G} 11 \mathrm{Q}}$ gene integration vector $\mathrm{pINmsmdh} \mathrm{G}^{\mathrm{G}} \mathrm{Q} \mathrm{Q}$ was constructed using the DNA fragments utilized to construct pINcgmdh except for $m s m d h^{\mathrm{G} 11 \mathrm{Q}}$ gene, which was amplified from pMS3-msmdhG11Q with primers P11-12. The $M$. succiniciproducens PALKPfrdmsmdh strain was constructed by replacing the promoter of $m s m d h\left(\mathrm{P}_{m d h}\right)$ in the PALK strain with the promoter of $f r d\left(\mathrm{P}_{f r d}\right)$. To construct the $\mathrm{P}_{\text {frd }}$ sequence integration vector pINPfrdmsmdh, the plasmid pSacHR06 containing the $s a c B$ gene was digested with XhoI and SacI. Next, the upstream and downstream homologous regions of the $\mathrm{P}_{m d h}$ sequence were amplified from the M. succiniciproducens PALK genomic DNA with primers P2223 and P24-25, respectively. The lox66-cat-lox77 cassette was amplified from pMSmulox with primers P26-27 and the $\mathrm{P}_{\text {frd }}$ sequence was amplified from pMS3 with primers P28-29. The linearized pSacHR06, $1 \mathrm{~kb}$ fragments of the upstream and downstream homologous regions of the $\mathrm{P}_{m d h}$ sequence, lox66-cat-lox77 cassette, and $\mathrm{P}_{\text {frd }}$ sequence fragments were assembled using Gibson assembly to finally construct pINPfrdmsmdh. Heterologous gene integrations into the PALK genome were carried out using the markerless chromosomal integration system ${ }^{43}$.

In silico analysis. Flux variability scanning based on enforced objective flux (FVSEOF) algorithm ${ }^{44}$ was performed using the $M$. succiniciproducens genomescale metabolic model that consists 686 metabolic reactions and 519 metabolites ${ }^{39}$ to identify amplification target genes for enhanced SA production in M. succiniciproducens (Supplementary Fig. 1a). FVSEOF algorithm searches the changes in metabolic flux solution space (i.e., min and max values of metabolic flux) of intracellular reaction in response to an increased flux toward the target chemical. Based on FVSEOF results, candidate enzymes that would ensure a minimal production rate of target chemical were selected from the slope of minimum flux values $\left(V_{\min }\right.$ slope), which was calculated by a linear regression between the enforced SA production rate and the minimal flux values $\left(V_{\min }\right)$ of the intracellular reactions (Supplementary Fig. 1b) ${ }^{45}$. The reactions that positively related with SA production rate were selected as target enzymes. Throughout the simulation, the glucose uptake rate was set to $10 \mathrm{mmol} \mathrm{gDCW}^{-1} \mathrm{~h}^{-1}$. Among 686 metabolic reactions in M. succiniciproducens genome-scale model, only four reactions showed increased flux patterns of minimum flux values for SA production; FRD, PCKA, $\mathrm{MDH}$, and FUMC (Supplementary Table 1).

In order to compare the amount of $\mathrm{NAD}^{+} / \mathrm{NADH}$ produced and consumed by the PALK strain from utilizing single (glucose) or dual (glucose and glycerol) carbon sources, in silico flux-sum analysis of the entire 515 cytosolic metabolites ${ }^{46}$ were carried out (Supplementary Fig. 13a). Flux-sum is the summation of all fluxes in or out of each metabolite. The cytosolic metabolites were only considered for flux-sum analysis to focus on glucose/glycerol metabolism taking place inside the cell. Parsimonious flux balance analysis ( $\mathrm{pFBA}$ ) was performed to calculate flux distributions generated from single or dual carbon source utilization while maximizing biomass production as an objective ${ }^{47}$ (Supplementary Fig. 13b). The $l d h A, p t a$, and $a c k A$ genes were deleted to mimic the genotype of PALK strain. Flux variability analysis $(\mathrm{FVA})^{48}$ was performed to calculate the upper and lower bounds of fluxes under $95 \%$ maximal growth rate with loopless solution ${ }^{49}$. To prevent the upper and lower bounds from being unrealistic, additional constraint was given to limit the sum of all absolute fluxes in FVA solution to be no larger than $10 \%$ of the sum of all absolute fluxes in pFBA solution. Throughout the simulation where glucose was used as a sole carbon source, the glucose uptake rate was set to $10 \mathrm{mmol} \mathrm{gDCW}^{-1} \mathrm{~h}^{-1}$. For the simulation where glucose and glycerol were utilized as dual carbon sources, the glucose and glycerol uptake rates were set to five and $10 \mathrm{mmolgDCW}^{-1} \mathrm{~h}^{-1}$, respectively. The uptake rates of dual carbon sources were set different to equate the number of carbons (glucose, six carbons; glycerol, three carbons) entering the metabolic system. All simulations were conducted in Python environment with Gurobi Optimizer 6.0 and GurobiPy package (Gurobi Optimization Inc., Houston, TX, USA). Reading, writing, and manipulation of the COBRA-compliant SBML files were implemented using COBRApy ${ }^{50}$.

Protein preparations. The genes encoding $M s \mathrm{MDH}$ (primers $\mathrm{P} 30-31$ ), AsMDH (primers P32-33), CgMDH (primers P34-35), EcMDH (primers P36-37), YlMDH (primers P38-39), mitochondrial ScMDH1 (primers P40-41), cytosolic ScMDH2 (primers P42-43), and glyoxysomal ScMDH3 (primers P44-45) from M. succiniciproducens, A. succinogenes, C. glutamicum, E. coli, Y. lipolytica, and S. cerevisiae were amplified from their chromosomal DNAs by PCR with primers listed in Supplementary Tables 8,9 . The PCR products were then inserted into pET30a (Novagen, Madison, WI, USA) with $6 \times$ His at the $\mathrm{C}$ terminus. The resulting expression vectors were transformed into the E. coli BL21 (DE3) ${ }^{\mathrm{T} 1 \mathrm{R}}$ strain and were grown in $\mathrm{LB}$ medium containing $100 \mathrm{mg} \mathrm{L}^{-1} \mathrm{Km}$ at $37^{\circ} \mathrm{C}$ to an $\mathrm{OD}_{600}$ (optical density at $600 \mathrm{~nm}$ ) of 0.6 . After induction with $1.0 \mathrm{mM} \mathrm{1-thio- \beta -D-galactopyr-}$ anoside (IPTG), cells were further cultured for $20 \mathrm{~h}$ at $18^{\circ} \mathrm{C}$ and harvested by centrifugation at $5000 \times g$ for $15 \mathrm{~min}$ at $4{ }^{\circ} \mathrm{C}$. The cell pellet was resuspended in $40 \mathrm{mM}$ Tris- $\mathrm{HCl}$ at $\mathrm{pH} 8.0$ and disrupted by ultra-sonication. The cell debris was removed by centrifugation at $11,000 \times \mathrm{g}$ for $1 \mathrm{~h}$ and the lysate was bound to Ni-NTA agarose column (Qiagen, Chatsworth, CA, USA). After washing with $40 \mathrm{mM}$ Tris- $\mathrm{HCl}$ containing $20 \mathrm{mM}$ imidazole at $\mathrm{pH} 8.0$, the proteins bound to the resin were eluted with $300 \mathrm{mM}$ imidazole in $40 \mathrm{mM}$ Tris- $\mathrm{HCl}$ at $\mathrm{pH}$ 8.0. Further purification was carried out using HiTrap Q ion exchange chromatography and size exclusion chromatography. The purified proteins were concentrated to $30 \mathrm{~g} \mathrm{~L}^{-1}$ in $40 \mathrm{mM}$ Tris- $\mathrm{HCl}$ at $\mathrm{pH} 8.0$ for crystallizations. Site-directed mutagenesis was performed using the QuikChange site-directed mutagenesis kit (Stratagene, La Jolla, CA, USA).

In vitro malate dehydrogenase activity assay. The activity of MDH was measured using a spectrophotometer at $340 \mathrm{~nm}$ by analyzing residual concentration of NADH (extinction coefficient of $\left.6.22 \mathrm{mM}^{-1} \mathrm{~cm}^{-1}\right)^{51}$. The relative activities of $\mathrm{MDHs}$ in comparison with the activity of $\mathrm{MsMDH}$ were measured using $0.5 \mathrm{~mL}$ of reaction mixture containing $0.1 \mathrm{M}$ Tris- $\mathrm{HCl}$ at $\mathrm{pH} 7.0,200 \mu \mathrm{M}$ NADH, $100 \mu \mathrm{M}$ oxaloacetate, and $3 \mathrm{nM}$ of various MDHs. For measurement of activity at various $\mathrm{pH}$, the same reaction mixture containing $0.1 \mathrm{M}$ BIS-Tris or CHES buffer were used for $\mathrm{pH} 5.0-6.0$ and 9.0-10.0, respectively, instead of $0.1 \mathrm{M}$ Tris-HCl. Based on the plotted kinetic data, the kinetic parameters were determined from non-linear regression analyses based on the modified Briggs-Haldane equation ${ }^{35,52}$ using OriginPro 2019 software (OriginLab, Northampton, MA, USA). All experiments were performed in triplicate at room temperature.

Cell extract assay. The enzyme activities in the cell extracts of M. succiniciproducens PALK and PALKcgmdh strains were measured using a spectrophotometer at $340 \mathrm{~nm}$ by analyzing residual concentration of NADH. The cell extract was obtained by collecting the cells $\left(\mathrm{OD}_{600}\right.$ of 50$)$ grown up to late exponential phase using centrifugation at $5566 \times g$ and $4{ }^{\circ} \mathrm{C}$, washing the cells twice with $0.1 \mathrm{M}$ Tris- $\mathrm{HCl}$ at $\mathrm{pH} 7.0$, and sonication in a final volume of $25 \mathrm{~mL}$. The enzyme activity in cell extract was measured at $\mathrm{pH} 7.0$ using $0.5 \mathrm{~mL}$ of reaction mixture containing $0.1 \mathrm{M}$ Tris- $\mathrm{HCl}, 200 \mu \mathrm{M} \mathrm{NADH}, 100 \mu \mathrm{M}$ OAA, and $10 \mu \mathrm{L}$ of cell extract lysate. The concentrations of the total proteins in the reaction mixtures containing the PALK and PALKcgmdh cell lysates were 8.8 and $7.6 \mu \mathrm{gL}^{-1}$, respectively.

Crystallization and structure determination. Crystallization of the purified proteins was initially performed using the following crystal screening kits: Index and PEG/Ion (Hampton Research) and Wizard I and II (Rigaku) using the hanging-drop vapor-diffusion technique at $20^{\circ} \mathrm{C}$. Drop size was $2 \mu \mathrm{L}$, which includes $1 \mu \mathrm{L}$ of protein solution and $1 \mu \mathrm{L}$ of reservoir solution, and the drop was equilibrated against $50 \mu \mathrm{L}$ of the reservoir solution. The $M s \mathrm{MDH}$ crystals, cocrystallized with $\mathrm{NAD}^{+}$(molar ratio 1:10) to capture the reaction product inside the $M s \mathrm{MDH}$ crystal structure, appeared in 16\% (w/v) PEG 3350 and 6\% (v/v) tacsimate at $\mathrm{pH}$ 6.0. The cryoprotectant solution was a mixture of $16 \%(\mathrm{w} / \mathrm{v})$ PEG $3350,6 \%(\mathrm{v} / \mathrm{v})$ tacsimate at $\mathrm{pH} 6.0$, and $30 \%(\mathrm{v} / \mathrm{v})$ glycerol. Data were collected under $100 \mathrm{~K}$ at Beamline 7A of the Pohang Accelerator Laboratory (Pohang, Republic of Korea $)^{53}$. Subsequently, the data were indexed, integrated, and scaled using the HKL2000 software suite ${ }^{54}$. The MsMDH crystals belonged to a space group P6422 with unit cell parameters of $a=80.09 \AA, b=80.09 \AA$, and $c=$ $193.15 \AA ; \alpha=\beta=90^{\circ}$ and $\gamma=120^{\circ}$. With one molecule of MsMDH per asymmetric unit, the Matthews coefficient was $\sim 2.58 \AA^{3} \mathrm{Da}^{-1}$, which corresponds to a solvent content of $\sim 52.04 \% 55$. The structure of $M s \mathrm{MDH}$ was determined by molecular replacement with the CCP4 version of MOLREP ${ }^{56}$ using the structure of 
an $\mathrm{MDH}$ from Haemophilus influenzae (PDB code 6BAL, 77\% sequence identity) as a search model. The model building was performed using the WinCoot program $^{57}$ and the refinement was performed with REFMAC $5^{58}$. The highest quality CgMDH crystals co-crystallized with L-malate and $\mathrm{NAD}^{+}$(molar ratio 1:20 and $1: 10)$ appeared in $20 \%(\mathrm{w} / \mathrm{v})$ PEG 3350, $0.1 \mathrm{M}$ HEPES at $\mathrm{pH} 7.5$, and $0.2 \mathrm{M}$ $\mathrm{MgCl}_{2} \cdot 6 \mathrm{H}_{2} \mathrm{O}$. The cryoprotectant solution includes $20 \%$ (w/v) PEG 3350, $0.1 \mathrm{M}$ HEPES at pH 7.5, $0.2 \mathrm{M} \mathrm{MgCl}_{2} \cdot 6 \mathrm{H}_{2} \mathrm{O}$, and $30 \%$ (v/v) glycerol. The $C g \mathrm{MDH}$ crystals belonged to the space group C2 with unit cell parameters of $a=102.93 \AA$, $b=116.94 \AA$, and $c=66.00 \AA ; \alpha=\gamma=90^{\circ}$ and $\beta=95.31^{\circ}$. Using one molecule of CgMDH per asymmetric unit, the Matthews coefficient was $\sim 2.87 \AA^{3} \mathrm{Da}^{-1}$, which corresponds to a solvent content of $\sim 56.77 \%^{55}$. The structure of $C g \mathrm{MDH}$ was determined by molecular replacement with the CCP4 version of MOLREP using the structure of a MDH from Mycobacterium tuberculosis (PDB code 4TVO, 57\% sequence identity) as a search model. The model was built following the procedure described above. Statistical analyses of the data are summarized in Supplementary Table 6. The refined models of $M s \mathrm{MDH}$ and $\mathrm{CgMDH}$ were deposited in the Protein Data Bank with PDB codes 6ITL (https://doi.org/10.2210/pdb6ITL/pdb) and 6ITK (https://doi.org/10.2210/pdb6ITK/pdb), respectively.

\section{Maximum likelihood of phylogenetic tree. Iterative searching for MDH-like} proteins was performed by Basic Local Alignment Search Tool (BLAST) in National Center for Biotechnology Information server using position-specific iterated BLAST method ${ }^{59}$. Multiple sequences alignment was performed by Clustal omega $^{60}$. The evolutionary history was inferred using the Maximum Likelihood method based on the Le_Gascuel_2008 model ${ }^{61}$. Initial trees for the heuristic search were obtained automatically by applying Neighbor-Join and BioNJ algorithms to a matrix of pairwise distances estimated using a JTT model and then selecting the topology with superior log likelihood value. A discrete Gamma distribution was used to model evolutionary rate differences among sites ( 5 categories, parameter $=1.0385)$. The rate variation model allowed $1.33 \%$ sites to be evolutionarily invariable. The tree with the highest log likelihood $(-58574.72)$ is shown in Supplementary Fig. 2. The phylogenetic tree is drawn to scale with branch lengths measured in the number of substitutions per site. The analysis involved 343 amino acid sequences. All positions with less than $95 \%$ site coverage were eliminated. That is, fewer than $5 \%$ alignment gaps, missing data, and ambiguous bases were allowed at any position. There were a total of 263 positions in the final dataset. Evolutionary analyses were conducted using MEGA X ${ }^{62}$.

\section{SA production using C. glutamicum and E. coli strains. The wild type and} engineered C. glutamicum strains were aerobically cultivated in Erlenmeyer flask equipped with $\mathrm{CO}_{2}$ gas inlet and outlet ports. Each flasks contained $100 \mathrm{~mL}$ BHIS medium. The aerobic cultivation was carried out for $6 \mathrm{~h}$ at $30^{\circ} \mathrm{C}$ with shaking because C. glutamicum strains cannot grow under anaerobic condition ${ }^{7}$. Then, IPTG was added to each flask to a final concentration of $0.5 \mathrm{mM}$ to initiate $\mathrm{CgMDH}$ expression. Finally, the flasks were charged with $\mathrm{CO}_{2}$ as headspace gas and incubated at $30^{\circ} \mathrm{C}$ with shaking for $10 \mathrm{~h}$. The wild type and engineered $E$. coli strains were anaerobically cultivated for $16 \mathrm{~h}$ in $100 \mathrm{~mL} \mathrm{LB}$ medium with $3 \mathrm{~g} \mathrm{~L}^{-1}$ glucose at $37^{\circ} \mathrm{C}$ with shaking. The initial cell concentrations of the wild type and engineered C. glutamicum and E. coli strains were $\mathrm{OD}_{600}$ of 0.2-0.25.

Fermentation and analytical procedures. The $M$. succiniciproducens strains were precultured in a $50 \mathrm{~mL}$ tube or a $500 \mathrm{~mL}$ Erlenmeyer flask equipped with $\mathrm{CO}_{2}$ gas inlet and outlet ports. Each tube and flask contained 20 and $270 \mathrm{~mL}$, respectively, of complex MH5 medium (per L: 2.78 g yeast extract, $2.78 \mathrm{~g}$ polypeptone, $0.18 \mathrm{~g} \mathrm{NaCl}$, $0.02 \mathrm{~g} \mathrm{CaCl}_{2} \cdot 2 \mathrm{H}_{2} \mathrm{O}, 0.2 \mathrm{~g} \mathrm{MgCl}_{2} \cdot 6 \mathrm{H}_{2} \mathrm{O}$, and $8.06 \mathrm{~g} \mathrm{~K}_{2} \mathrm{HPO}_{4}$, and $9.15 \mathrm{~g} \mathrm{NaHCO}_{3}$ ). After adjusting the $\mathrm{pH}$ of the complex medium to 7.0 using $5 \mathrm{M} \mathrm{NaOH}$ and flushing with $\mathrm{CO}_{2}$, it was heat sterilized at $121^{\circ} \mathrm{C}$ for $15 \mathrm{~min}$. Carbon sources (glucose and glycerol) were separately sterilized and added into the culture medium to a final concentration of $10 \mathrm{~g} \mathrm{~L}^{-1}$. Then, $2.5 \mathrm{~mL}$ of glycerol stock culture $(15 \%$, $\mathrm{w} / \mathrm{v}$ ), which was stored in a deep freezer at $-70^{\circ} \mathrm{C}$, was inoculated into a $50 \mathrm{~mL}$ test tube containing complex medium and carbon source. The test tube charged with $\mathrm{CO}_{2}$ as headspace gas was incubated in a static incubator at $39^{\circ} \mathrm{C}$. Next, $5 \%(\mathrm{v} / \mathrm{v})$ of the cultured cell broth was transferred to the $500 \mathrm{~mL}$ Erlenmeyer flask containing complex medium and carbon source for further cultivation using the same condition as test tube culture.

Fed-batch fermentations were carried out in a $6.6 \mathrm{~L}$ Bioflo 3000 bioreactor (New Brunswick Scientific Co., Edison, NJ, USA) with a working volume of $2.5 \mathrm{~L}$. The $\mathrm{CDM}$ used in this study contained (per L) $1 \mathrm{~g} \mathrm{NaCl}, 0.02 \mathrm{~g} \mathrm{CaCl}_{2} \cdot 2 \mathrm{H}_{2} \mathrm{O}, 2 \mathrm{~g}$ $\left(\mathrm{NH}_{4}\right)_{2} \mathrm{SO}_{4}, 0.5 \mathrm{~g}$ alanine, $0.5 \mathrm{~g}$ asparagine, $0.005 \mathrm{~g}$ biotin, $0.5 \mathrm{~g}$ methionine, $0.005 \mathrm{~g}$ Ca-pantothenate, $0.005 \mathrm{~g}$ pyridoxine- $\mathrm{HCl}, 0.005 \mathrm{~g}$ thiamine, $0.2 \mathrm{~g} \mathrm{MgCl}_{2} \cdot 6 \mathrm{H}_{2} \mathrm{O}$, $1.5 \mathrm{~g} \mathrm{~K}_{2} \mathrm{HPO}_{4}, 9.997 \mathrm{~g} \mathrm{NaHCO}_{3}, 0.005 \mathrm{~g}$ ascorbic acid, $0.5 \mathrm{~g}$ aspartic acid, $0.5 \mathrm{~g}$ cysteine, $0.005 \mathrm{~g}$ nicotinic acid, $0.5 \mathrm{~g}$ proline, $0.5 \mathrm{~g}$ serine, and $5 \mathrm{~mL}$ trace metal solution. The trace metal solution contained (per L) $5 \mathrm{~mL} \mathrm{HCl}, 10 \mathrm{~g} \mathrm{FeSO}_{4} \cdot 7 \mathrm{H}_{2} \mathrm{O}$, $2.25 \mathrm{~g} \mathrm{ZnSO}_{4} \cdot 7 \mathrm{H}_{2} \mathrm{O}, 1 \mathrm{~g} \mathrm{CuSO}_{4} \cdot 5 \mathrm{H}_{2} \mathrm{O}, 0.5 \mathrm{~g} \mathrm{MnSO}_{4} \cdot 5 \mathrm{H}_{2} \mathrm{O}, 0.23 \mathrm{~g} \mathrm{Na}_{2} \mathrm{~B}_{4} \mathrm{O}_{7} \cdot 10 \mathrm{H}_{2} \mathrm{O}$, and $0.1 \mathrm{~g}\left(\mathrm{NH}_{4}\right)_{6} \mathrm{Mo}_{7} \mathrm{O}_{24}$. The $\mathrm{CDM}$ was supplemented with $18.02 \mathrm{~g} \mathrm{~L}^{-1}(100 \mathrm{mM})$ glucose and/or $4.60 \mathrm{~g} \mathrm{~L}^{-1}(50 \mathrm{mM})$ glycerol. Antibiotics were added to the following concentration when necessary: Ap $\left(50 \mathrm{mg} \mathrm{L}^{-1}\right)$ and $\mathrm{Km}\left(25 \mathrm{mg} \mathrm{L}^{-1}\right)$. The feeding solution was composed of $900 \mathrm{~g} \mathrm{~L}^{-1}$ glucose and/or glycerol. Fed-batch fermentation was initiated by inoculation of $300 \mathrm{~mL}$ of precultured broth, giving the initial $\mathrm{OD}_{600}$ of $0.2-0.3$. Temperature and agitation speed of four flat blade turbine impellers in the bioreactor were controlled at $39^{\circ} \mathrm{C}$ and $200 \mathrm{rpm}$, respectively. The $\mathrm{pH}$ of the fermentation broth was controlled at 6.5 by automatic addition of a mixture of $1.57 \mathrm{M}$ ammonia solution and $6.84 \mathrm{M} \mathrm{MgOH}_{2}$ solution. The bioreactor was continuously sparged with industrial-grade $\mathrm{CO}_{2}$ gas at a flow rate of $0.2 \mathrm{vvm}\left(\mathrm{CO}_{2}\right.$ volume per working volume per $\left.\mathrm{min}\right)$ by a mass flow controller. Fed-batch fermentations were performed in a semi-continuous feeding mode, which the feeding solution was supplied into the bioreactor via a peristaltic pump, to maintain the carbon source concentration at $5-15 \mathrm{~g} \mathrm{~L}^{-1}$ for substrate inhibition minimization by changing the feeding rate. For higher inoculum fedbatch fermentation, cells were harvested from a $10 \mathrm{~L}$ batch fermentation and were resuspended using $200 \mathrm{~mL}$ of CDM. The rest of the fermentation procedures were identical to a normal fed-batch fermentation except for the initial glucose and glycerol concentrations, which were 36.4 and $9.2 \mathrm{~g} \mathrm{~L}^{-1}$, respectively.

The concentrations of glucose, glycerol, and fermentative products were immediately monitored using ProStar 210 HPLC (Varian, CA, USA) accompanied with ProStar 320 UV/visible-light (Varian) and Shodex RI-71 refractive index (Shodex, Tokyo, Japan) detectors over the entire period of fermentation. The MetaCarb $87 \mathrm{H}$ column $(300 \times 7.8 \mathrm{~mm}$; Agilent, CA, USA $)$ was eluted isocratically (flow rate $=0.6 \mathrm{~mL} \mathrm{~min}^{-1}$ ) using $0.01 \mathrm{~N} \mathrm{H}_{2} \mathrm{SO}_{4}$ at $60^{\circ} \mathrm{C}$. Cell growth was monitored by measuring $\mathrm{OD}_{600}$ using Ultrospec 3000 spectrophotometer (GE Healthcare, Chalfont St. Giles, UK). Optical density was converted to a cell concentration defined as gram dry cell weight (gDCW) using the predetermined standard curve $\left(1 \mathrm{OD}_{600}=0.451 \mathrm{gDCW} \mathrm{L}^{-1}\right)$. When glucose and glycerol were coutilized, the SA yield was calculated based on glucose equivalent (mol SA per mol glucose equivalent) for clear comparison. As the number of carbons in glucose and glycerol differ by a factor of 2, the amount of glycerol consumed (mol) was converted to mol glucose equivalent to calculate the total amount of carbon sources consumed during the course of fed-batch fermentation.

Measurement of intracellular $\mathbf{p H}$. The intracellular $\mathrm{pH}$ of the M. succiniciproducens PALK, PALKcgmdh, and PALKmsmdh G11Q strains were determined using pHrodo $^{\mathrm{TM}}$ Green AM Intracellular $\mathrm{pH}$ Indicator kit (Cat. no. P35373, Invitrogen, Carlsbad, CA, USA). The cells were collected at late exponential phase using centrifugation at $5566 \times g$ and $4{ }^{\circ} \mathrm{C}$. The cells were then washed with Live Cell Imaging Solution (Invitrogen) to remove the culture medium. Next, the cells were resuspended with the $\mathrm{pHrodo}^{\mathrm{TM}} \mathrm{AM}$ staining solution containing $\mathrm{pH}$-sensitive fluorogenic probes, which exhibit increasing fluorescence with decrease in $\mathrm{pH}$, and incubated at $37^{\circ} \mathrm{C}$ for $30 \mathrm{~min}$. The $\mathrm{pH}$-sensitive fluorogenic probe was modified with acetoxymethyl ester enabling the probe to easily permeate the cell membrane and to be retained within the intracellular space ${ }^{63}$. Finally, the fluorescence intensity of the probe inside the cells was measured using the Spark ${ }^{\circledR}$ multimode microplate reader (Tecan, Männedorf, Switzerland) at excitation/emission of 509/ $533 \mathrm{~nm}$. A calibration curve, which shows the fluorescence intensity emitted by the fluorogenic probe inside the cells when the intracellular $\mathrm{pH}$ ranged from 4.5 to 7.5 , was derived using the Intracellular pH Calibration Buffer kit (Cat. no. P35379, Invitrogen) and was used to quantify the intracellular $\mathrm{pH}$ of the M. succiniciproducens PALK, PALKcgmdh, and PALKmsmdh ${ }^{\mathrm{G} 11 \mathrm{Q}}$ strains.

Measurement of intracellular OAA concentration. Before analyzing the intracellular OAA concentration, the intracellular metabolites were extracted from the $M$. succiniciproducens PALK strain using a modified version of the quenching/extraction protocol reported from previous study ${ }^{64}$. Briefly, cells were cultivated to the late exponential phase and $60 \mathrm{~mL}$ of culture broth was mixed with $180 \mathrm{~mL}$ of ice-cold quenching solution ( $60 \% \mathrm{v} / \mathrm{v}$ aqueous methanol). The mixture was immediately centrifuged at $5566 \times g$ and $0{ }^{\circ} \mathrm{C}$ for $10 \mathrm{~min}$ to remove supernatant. Next, the cell pellet was treated with liquid nitrogen and freeze-dried. Extraction of intracellular metabolites was performed by treating the dried cells with $0.8 \mathrm{~mL}$ of cold $1 \mathrm{M}$ perchloric acid. Then, the treated cells were centrifuged at $15,871 \times g$ and $0{ }^{\circ} \mathrm{C}$ for $15 \mathrm{~min}$ to collect the supernatant. Cell debris was resuspended using deionized water and filtered using a preweighed $0.2-\mu \mathrm{m}$ membrane filter (Whatman International Ltd., Kent, UK). The filtered membrane filter was fully dried in $70^{\circ} \mathrm{C}$ oven and weighed. Then gDCW of the sample analyzed was determined by subtracting the weight of membrane filter from the total weight. Finally, the supernatant containing intracellular metabolites was neutralized using $0.4 \mathrm{~mL}$ of cold $3 \mathrm{M} \mathrm{KHCO}_{3}$ and centrifuged at $15,871 \times g$ and $0^{\circ} \mathrm{C}$ for $15 \mathrm{~min}$ to remove precipitate.

The amount of intracellular OAA in the supernatant was quantified using the OAA assay kit (Sigma-Aldrich, St. Louis, MO, USA). The probe in the reaction mixture that is originally colorless changes to an intensely colored and fluorescent product once exposed to pyruvate, which is converted from OAA (one of the metabolites in the supernatant) by an enzyme mix. The reaction mixture contained $2 \mu \mathrm{L}$ of enzyme mix, $2 \mu \mathrm{L}$ of developer, $2 \mu \mathrm{L}$ of OAA probe, and $44 \mu \mathrm{L}$ of supernatant, which was previously diluted (1:1) using assay buffer to adjust the fluorescence for correct calculation of OAA using curve fitting method. The assay buffer, enzyme mix, developer, and OAA probe were provided in the OAA assay kit. The fluorescence intensity of the probe was measured using the Spark ${ }^{\circledR}$ multimode microplate reader at excitation/emission of $535 / 587 \mathrm{~nm}$. As intracellular pyruvate already exists in the M. succiniciproducens PALK strain, the fluorescence intensity of the probe from a reaction mixture not containing enzyme mix (control) was also analyzed to determine background fluorescence. The 
background fluorescence was subtracted from the fluorescence intensity of the probe from a reaction mixture containing enzyme mix. A calibration curve showing the fluorescence intensity emitted by the probe when the amount of OAA ranged from 0 to $1.0 \mathrm{~mol}$, was also generated and used to quantify the amount of intracellular OAA in the sample analyzed. Finally, the volume and dry mass of a single cell of M. succiniciproducens PALK strain were measured (described below) and were used to calculate the intracellular OAA concentration in a single cell.

Measurement of single cell volume and dry mass. The single cell volume and dry mass of M. succiniciproducens PALK strain were analyzed using 3D quantitative phase imaging (QPI) and quantitative image analysis. The 3D QPI of live cells (cultured up to late exponential phase) were performed using a commercial holotomography HT$2 \mathrm{H}$ (Tomocube Inc., Daejeon, Republic of Korea), which is based on Mach-Zehnder interferometry equipped with a digital micromirror device (DMD). A coherent monochromatic laser $(\lambda=532 \mathrm{~nm})$ was divided into two paths, a reference beam and a sample beam, using a $2 \times 2$ single-mode fiber coupler. A 3D refractive index (RI) tomogram was reconstructed from multiple $2 \mathrm{D}$ holographic images acquired from 49 illumination conditions, a normal incidence, and 48 azimuthally symmetric directions with a polar angle $\left(64.5^{\circ}\right)$. The DMD was used to control the angle of an illumination beam impinging onto the sample $e^{65}$. The diffracted beams from the sample were collected using a high numerical aperture $(\mathrm{NA}=1.2)$ objective lens UPLSAP $60 \mathrm{XW}$ (Olympus, Tokyo, Japan). The off-axis hologram was recorded by a CMOS image sensor FL3-U3-13Y3MC (FLIR Systems, Wilsonville, Oregon, USA). The visualization of 3D RI maps was carried out using a TomoStudio ${ }^{\mathrm{TM}}$ software (Tomocube Inc.) Detailed information on the principle of optical diffraction tomography and a reconstructed MATLAB code can be found elsewhere ${ }^{66-69}$. Each cell detected from 3D QPI was segmented using RI thresholds determined by Otsu's method and marker-controlled watershed segmentation. The single cell volume of M. succiniciproducens PALK strain was calculated based on the physical size of individual voxels. The single cell dry mass of $M$. succiniciproducens PALK strain was calculated using $0.19 \mathrm{~mL} \mathrm{~g}^{-1}$ as refractive index increment ${ }^{70,71}$.

Reporting summary. Further information on research design is available in the Nature Research Reporting Summary linked to this article.

\section{Data availability}

Data supporting the findings of this work are available within the paper and its Supplementary Information file. A reporting summary for this Article is available as a Supplementary Information file. The datasets generated and analyzed during the current study are available from the corresponding author upon request. Information on the PDB accessions 6ITL and 6ITK can also be found at https://doi.org/10.2210/ pdb6ITL/pdb and https://doi.org/10.2210/pdb6ITK/pdb, respectively. The source data underlying Fig. 3, Supplementary Figs. 10, 11, 14, 15, and 16, and Supplementary Table 10 are provided as a Source Data file.

Received: 1 December 2019; Accepted: 31 March 2020;

Published online: 23 April 2020

\section{References}

1. Ahn, J. H., Jang, Y.-S. \& Lee, S. Y. Production of succinic acid by metabolically engineered microorganisms. Curr. Opin. Biotechnol. 42, 54-66 (2016)

2. Murase, M. et al. Method of producing succinic acid with bacterium comprising a modified fumarate reductase gene or a modified succinate dehydrogenase gene. US patent, US7763447B2 (2010).

3. Grabar, T., Gong, W. \& Yocum, R. R. Metabolic evolution of Escherichia coli strains that produce organic acids. US patent, US8871489B2 (2014).

4. Van De, Graaf, et al. for the crystallization of succinic acid. US patent, US20120238722A1 (2012).

5. Kuhnert, P., Scholten, E., Haefner, S., Mayor, D. \& Frey, J. Basfia succiniciproducens gen. nov., sp. nov., a new member of the family Pasteurellaceae isolated from bovine rumen. Int. J. Syst. Evol. Microbiol. 60 44-50 (2010).

6. Guettler, M. V., Jain, M. K. \& Rumler, D. Method for making succinic acid, bacterial variants for use in the process, and methods for obtaining variants. US patent, US5573931A (1996)

7. Litsanov, B., Brocker, M. \& Bott, M. Toward homosuccinate fermentation: metabolic engineering of Corynebacterium glutamicum for anaerobic production of succinate from glucose and formate. Appl. Environ. Microbiol. 78, 3325-3337 (2012).

8. Lee, S. J. et al. Metabolic engineering of Escherichia coli for enhanced production of succinic acid, based on genome comparison and in silico gene knockout simulation. Appl. Environ. Microbiol. 71, 7880-7887 (2005).

9. Lee, J. W. et al. Homo-succinic acid production by metabolically engineered Mannheimia succiniciproducens. Metab. Eng. 38, 409-417 (2016).
10. Agren, R., Otero, J. M. \& Nielsen, J. Genome-scale modeling enables metabolic engineering of Saccharomyces cerevisiae for succinic acid production. J. Ind. Microbiol. Biotechnol. 40, 735-747 (2013).

11. Li, C., Gao, S., Yang, X. \& Lin, C. S. K. Green and sustainable succinic acid production from crude glycerol by engineered Yarrowia lipolytica via agricultural residue based in situ fibrous bed bioreactor. Bioresour. Technol. 249, 612-619 (2018).

12. Vemuri, G., Eiteman, M. \& Altman, E. Succinate production in dual-phase Escherichia coli fermentations depends on the time of transition from aerobic to anaerobic conditions. J. Ind. Microbiol. Biotechnol. 28, 325-332 (2002).

13. Kim, W. J., Ahn, J. H., Kim, H. U., Kim, T. Y. \& Lee, S. Y. Metabolic engineering of Mannheimia succiniciproducens for succinic acid production based on elementary mode analysis with clustering. Biotechnol. J. 12, https://doi.org/10.1002/biot.201600701 (2017).

14. Lee, S. J., Song, H. \& Lee, S. Y. Genome-based metabolic engineering of Mannheimia succiniciproducens for succinic acid production. Appl. Environ. Microbiol. 72, 1939-1948 (2006).

15. Choi, S. et al. Highly selective production of succinic acid by metabolically engineered Mannheimia succiniciproducens and its efficient purification. Biotechnol. Bioeng. 113, 2168-2177 (2016).

16. Ahn, J. H., Bang, J., Kim, W. J. \& Lee, S. Y. Formic acid as a secondary substrate for succinic acid production by metabolically engineered Mannheimia succiniciproducens. Biotechnol. Bioeng. 114, 2837-2847 (2017).

17. Ahn, J. H., Lee, J. A., Bang, J. \& Lee, S. Y. Membrane engineering via transunsaturated fatty acids production improves succinic acid production in Mannheimia succiniciproducens. J. Ind. Microbiol. Biotechnol. 45, 555-556 (2018).

18. Hong, S. H. et al. The genome sequence of the capnophilic rumen bacterium Mannheimia succiniciproducens. Nat. Biotechnol. 22, 1275-1281 (2004).

19. Liang, L.-y et al. Increased production of succinic acid in Escherichia coli by overexpression of malate dehydrogenase. Biotechnol. Lett. 33, 2439-2444 (2011).

20. Wang, W., Li, Z., Xie, J. \& Ye, Q. Production of succinate by a pflB $l d h A$ double mutant of Escherichia coli overexpressing malate dehydrogenase. Bioprocess Biosyst. Eng. 32, 737 (2009).

21. Yan, D. et al. Construction of reductive pathway in Saccharomyces cerevisiae for effective succinic acid fermentation at low $\mathrm{pH}$ value. Bioresour. Technol. 156, 232-239 (2014).

22. McAlister-Henn, L., Steffan, J. S., Minard, K. I. \& Anderson, S. L. Expression and function of a mislocalized form of peroxisomal malate dehydrogenase (MDH3) in yeast. J. Biol. Chem. 270, 21220-21225 (1995).

23. Madem, D. Molecular evolution within the L-malate and L-lactate dehydrogenase super-family. J. Mol. Evol. 54, 825-840 (2002).

24. MacDonald, M. J. Evidence for the malate aspartate shuttle in pancreatic islets. Arch. Biochem. Biophys. 213, 643-649 (1982).

25. Lopez-Calcagno, P. E. et al. Cloning, expression and biochemical characterization of mitochondrial and cytosolic malate dehydrogenase from Phytophthora infestans. Mycol. Res. 113, 771-781 (2009).

26. Wu, J. L. et al. Effects of L-malate on physical stamina and activities of enzymes related to the malate-aspartate shuttle in liver of mice. Physiol. Res. 56, 213-220 (2007).

27. Lee, J. A., Ahn, J. H. \& Lee, S. Y. in Comprehensive Biotechnology (ed. Moo-Young, M.) Vol. 3 (Elsevier, Amsterdam, 2019).

28. Dasika, S. K., Vinnakota, K. C. \& Beard, D. A. Determination of the catalytic mechanism for mitochondrial malate dehydrogenase. Biophys. J. 108, 408-419 (2015).

29. Lee, P., Lee, S., Hong, S. \& Chang, H. Isolation and characterization of a new succinic acid-producing bacterium, Mannheimia succiniciproducens MBEL55E, from bovine rumen. Appl. Microbiol. Biotechnol. 58, 663-668 (2002).

30. Oh, Y. H., Oh, I. J., Jung, C., Lee, S. Y. \& Lee, J. The effect of protectants and $\mathrm{pH}$ changes on the cellular growth and succinic acid yield of Mannheimia succiniciproducens LPK7. J. Microbiol. Biotechnol. 20, 1677-1680 (2010).

31. Molenaar, D., van der Rest, M. E., Drysch, A. \& Yücel, R. Functions of the membrane-associated and cytoplasmic malate dehydrogenases in the citric acid cycle of Corynebacterium glutamicum. J. Bacteriol. 182, 6884-6891 (2000).

32. Raval, D. N. \& Wolfe, R. G. Malic dehydrogenase. V. Kinetic studies of substrate inhibition by oxalacetate. Biochemistry 2, 220-224 (1963).

33. Bernstein, L. H., Grisham, M. B., Cole, K. D. \& Everse, J. Substrate inhibition of the mitochondrial and cytoplasmic malate dehydrogenases. J. Biol. Chem. 253, 8697-8701 (1978).

34. De Arriaga, D., Teixido, F., Busto, F. \& Soler, J. The nature of the substrate inhibition of cytoplasmic malate dehydrogenase from Phycomyces blakesleeanus. Biochim. Biophys. Acta Protein Struct. Mol. Enzymol. 784, 158-163 (1984).

35. Mahmoud, Y. A. G., Abuelsouod, S. M. \& Niehaus, W. G. Purification and characterization of malate dehydrogenase from Cryptococcus-Neoformans. Arch. Biochem. Biophys. 322, 69-75 (1995). 
36. Goward, C. R. \& Nicholls, D. J. Malate-dehydrogenase: a model for structure, evolution, and catalysis. Protein Sci. 3, 1883-1888 (1994).

37. Gu, P. et al. A rapid and reliable strategy for chromosomal integration of gene (s) with multiple copies. Sci. Rep. 5, 9684 (2015).

38. Jang, Y. S. et al. Construction and characterization of shuttle vectors for succinic acid producing rumen bacteria. Appl. Environ. Microbiol. 73, 5411-5420 (2007).

39. Blankschien, M. D., Clomburg, J. M. \& Gonzalez, R. Metabolic engineering of Escherichia coli for the production of succinate from glycerol. Metab. Eng. 12, 409-419 (2010).

40. Yazdani, S. S. \& Gonzalez, R. Anaerobic fermentation of glycerol: a path to economic viability for the biofuels industry. Curr. Opin. Biotechnol. 18, 213-219 (2007).

41. Chen, C. et al. Structure-based mutational studies of substrate inhibition of betaine aldehyde dehydrogenase BetB from Staphylococcus aureus. Appl. Environ. Microbiol. 80, 3992-4002 (2014).

42. Gibson, D. G. et al. Enzymatic assembly of DNA molecules up to several hundred kilobases. Nat. Methods 6, 343-345 (2009).

43. Kim, J. M., Lee, K. H. \& Lee, S. Y. Development of a markerless gene knockout system for Mannheimia succiniciproducens using a temperature-sensitive plasmid. FEMS Microbiol. Lett. 278, 78-85 (2008).

44. Park, J. M. et al. Flux variability scanning based on enforced objective flux for identifying gene amplification targets. BMC Syst. Biol. 6, 106 (2012).

45. Tepper, N. \& Shlomi, T. Predicting metabolic engineering knockout strategies for chemical production: accounting for competing pathways. Bioinformatics 26, 536-543 (2009).

46. Choi, S. Y. et al. One-step fermentative production of poly(lactate-co-glycolate) from carbohydrates in Escherichia coli. Nat. Biotechnol. 34, 435-440 (2016).

47. Lewis, N. et al. Omic data from evolved E. coli are consistent with computed optimal growth from genome-scale models. Mol. Syst. Biol. 6, 390 (2010).

48. Mahadevan, R. \& Schilling, C. The effects of alternate optimal solutions in constraint-based genome-scale metabolic models. Metab. Eng. 5, 264-276 (2003).

49. Broddrick, J. et al. Predicting the metabolic capabilities of Synechococcus elongatus PCC 7942 adapted to different light regimes. Metab. Eng. 52, 42-56 (2019).

50. Ebrahim, A., Lerman, J. A., Palsson, B. O. \& Hyduke, D. R. COBRApy: constraints-based reconstruction and analysis for python. BMC Syst. Biol. 7, 74 (2013).

51. Horecker, B. L. \& Kornberg, A. The extinction coefficients of the reduced band of pyridine nucleotides. J. Biol. Chem. 175, 385-390 (1948).

52. Eszes, C. M., Sessions, R. B., Clarke, A. R., Moreton, K. M. \& Holbrook, J. J. Removal of substrate inhibition in a lactate dehydrogenase from human muscle by a single residue change. FEBS Lett. 399, 193-197 (1996).

53. Park, S.-Y., Ha, S.-C. \& Kim, Y.-G. The protein crystallography beamlines at the pohang light source II. Biodesign 5, 30-34 (2017).

54. Otwinowski, Z. \& Minor, W. Processing of X-ray diffraction data collected in oscillation mode. Methods Enzymol. 276, 307-326 (1997).

55. Matthews, B. W. Solvent content of protein crystals. J. Mol. Biol. 33, 491-497 (1968).

56. Vagin, A. \& Teplyakov, A. Molecular replacement with MOLREP. Acta Crystallogr. D Biol. Crystallogr. 66, 22-25 (2010).

57. Emsley, P. \& Cowtan, K. Coot: model-building tools for molecular graphics. Acta Crystallogr. D Biol. Crystallogr. 60, 2126-2132 (2004).

58. Murshudov, G. N., Vagin, A. A. \& Dodson, E. J. Refinement of macromolecular structures by the maximum-likelihood method. Acta Crystallogr. D Biol. Crystallogr. 53, 240-255 (1997).

59. Altschul, S. F. et al. Gapped BLAST and PSI-BLAST: a new generation of protein database search programs. Nucleic Acids Res 25, 3389-3402 (1997).

60. Sievers, F. et al. Fast, scalable generation of high-quality protein multiple sequence alignments using Clustal Omega. Mol. Syst. Biol. 7, 539 (2011).

61. Le, S. Q. \& Gascuel, O. An improved general amino acid replacement matrix Mol. Biol. Evol. 25, 1307-1320 (2008).

62. Kumar, S., Stecher, G., Li, M., Knyaz, C. \& Tamura, K. MEGA X: Molecular evolutionary genetics analysis across computing platforms. Mol. Biol. Evol. 35, 1547-1549 (2018).

63. Loiselle, F. B., \& Casey, J. R. in Membrane Trasporters in Drug Discovery and Development. Methods in Molecular Biology (ed. Yan, Q.) Vol. 637, 311-331 (Springer, Berlin, 2010).

64. Nor 'Aini, A. R., Shirai, Y., Hassan, M. A. \& Shimizu, K. Investigation on the metabolic regulation of pgi gene knockout Escherichia coli by enzyme activities and intracellular metabolite concentrations. Malays. J. Microbiol. 2, 24-31 (2006).

65. Shin, S., Kim, K., Yoon, J. \& Park, Y. Active illumination using a digital micromirror device for quantitative phase imaging. Opt. Lett. 40, 5407-5410 (2015).

66. Wolf, E. Three-dimensional structure determination of semi-transparent objects from holographic data. Opt. Commun. 1, 153-156 (1969).
67. Kim, K. et al. High-resolution three-dimensional imaging of red blood cells parasitized by Plasmodium falciparum and in situ hemozoin crystals using optical diffraction tomography. J. Biomed. Opt. 19, 011005 (2014).

68. Lim, J. W. et al. Comparative study of iterative reconstruction algorithms for missing cone problems in optical diffraction tomography. Opt. Express 23, 16933-16948 (2015).

69. Park, Y. K., Depeursinge, C. \& Popescu, G. Quantitative phase imaging in biomedicine. Nat. Photonics 12, 578-589 (2018).

70. Barer, R. Determination of dry mass, thickness, solid and water concentration in living cells. Nature 172, 1097-1098 (1953).

71. Popescu, G. et al. Optical imaging of cell mass and growth dynamics. Am. J. Physiol. Cell Physiol. 295, C538-C544 (2008).

\section{Acknowledgements}

We thank Tomocube Inc., Yang, S., and Choi, K.R. for helping us analyze the single cell mass and volume. This work was supported by the Technology Development Program to Solve Climate Changes on Systems Metabolic Engineering for Biorefineries (NRF2012M1A2A2026556 and NRF-2012M1A2A2026557) from the Ministry of Science and ICT (MSIT) through the National Research Foundation (NRF) of Korea. This work was further supported by the C1 Gas Refinery Program (NRF-2016M3D3A1A01913250) from MSIT through NRF.

\section{Author contributions}

J.H.A., H.S., K.-J.K., and S.Y.L. designed research. J.H.A., H.S., W.P., J.A.L., W.J.K., G.B.K., and J.S. performed research. W.P. performed X-ray crystallographic experiment. J.H.A. and H.S. analyzed data. J.H.A., H.S., K.-J.K., and S.Y.L. wrote the paper.

\section{Competing interests}

Authors declare that they have competing financial interests as the M. succiniciproducens strains described in this paper are covered by patents registered including KR1007803240000, AU20077277593, BE2054502, BRPI07138393, CA2659246, CN200780036066.4, DE2054502, IDP000039187, IT2054502, JP5421103, MX2009001004, NZ575237, PT2054502, RU2415942, SE2054502, US9217138, VN159559, ZA200901254, NL2054502, AU211296791, CA2809942, CN201180051937.6, EP2612905, JP5805768, MX344549, NZ607585, OA201301510, PH12013500378, RU2537003, US8691516, VN1201300959, KR1012215570000, ZA201301510, DE602011031069.0, DK2612905, ES2612905, FR2612905, GB2612905, IT502016000127739, NL2612905, SE2612905, KR1006037490000, JP4672671, AR049175B1, AU2004292624, CA2545363, CL51213, CN200480034984.X, DE1692271, DK1692271, EP1692271, FR1692271, GB1692271, ID0025939, IN228001, MY148492A, NL1692271, NZ547305, PH12006500980, RU2376369, TWI357929, US7470530, VN8193, ZA200604108, KR1003722180000, JP3759104, and US7063968, or filed including KR1020180120696, US16490515, EP19762287, IN514CHENP2009, MY20092744, PH12009500147, ID00201300864, IN1534CHENP2013, MYPI2013000662, BR1120130046520.0, BRPI04164377, and TH501002121.

\section{Additional information}

Supplementary information is available for this paper at https://doi.org/10.1038/s41467020-15839-z.

Correspondence and requests for materials should be addressed to K.-J.K. or S.Y.L.

Peer review information Nature Communications thanks the anonymous reviewers for their contribution to the peer review of this work. Peer reviewer reports are available.

Reprints and permission information is available at http://www.nature.com/reprints

Publisher's note Springer Nature remains neutral with regard to jurisdictional claims in published maps and institutional affiliations.

Open Access This article is licensed under a Creative Commons Attribution 4.0 International License, which permits use, sharing, adaptation, distribution and reproduction in any medium or format, as long as you give appropriate credit to the original author(s) and the source, provide a link to the Creative Commons license, and indicate if changes were made. The images or other third party material in this article are included in the article's Creative Commons license, unless indicated otherwise in a credit line to the material. If material is not included in the article's Creative Commons license and your intended use is not permitted by statutory regulation or exceeds the permitted use, you will need to obtain permission directly from the copyright holder. To view a copy of this license, visit http://creativecommons.org/ licenses/by/4.0/.

(C) The Author(s) 2020 